\title{
Brain Tumors and Syndromes in Children
}

\author{
Fonnet E. Bleeker ${ }^{1}$ Saskia M. J. Hopman ${ }^{2}$ Johannes H. M. Merks ${ }^{2}$ Cora M. Aalfs ${ }^{1}$ \\ Raoul C. M. Hennekam¹,3
}

1 Department of Clinical Genetics, Academic Medical Center, University of Amsterdam, Amsterdam, The Netherlands

Address for correspondence Fonnet E. Bleeker, MD, PhD, Department of Clinical Genetics, Room M0-205, Academic Medical Center, University of Amsterdam, Meibergdreef 9, 1105 AZ, Amsterdam,

2 Department of Paediatric Oncology, Emma Children's Hospital, Academic Medical Center, University of Amsterdam, Amsterdam, The Netherlands

${ }^{3}$ Department of Paediatrics, Emma Children's Hospital, Academic The Netherlands (e-mail: f.e.bleeker@amc.uva.nl).

Medical Center, University of Amsterdam, Amsterdam,

The Netherlands

Neuropediatrics 2014;45:137-161.

\begin{abstract}
(Brain) tumors are usually a disorder of aged individuals. If a brain tumor occurs in a child, there is a possible genetic susceptibility for this. Such genetic susceptibilities often show other signs and symptoms. Therefore, every child with a brain tumor should be carefully evaluated for the presence of a "tumor predisposition syndrome." Here, we provide an overview of the various central nervous system tumors that occur in children with syndromes and of the various syndromes that occur in children with brain tumor.

Keywords

- infant

- child

- brain tumor

- gene

- genetic

- malformation

- syndrome

- surveillance Our aim is to facilitate recognition of syndromes in children with a brain tumor and early diagnosis of brain tumors in children with syndromes. Diagnosing tumor predisposition syndromes in children may have important consequences for prognosis, treatment, and screening for subsequent malignancies and nontumor manifestations. We discuss pitfalls in clinical and molecular diagnoses, and the consequences of diagnosing a hereditary disorder for family members. Our improved knowledge of cancer etiology is increasingly translated into management strategies in syndromes in general and will likely lead in the near future to personalized therapeutic approaches for tumor predisposition syndromes.
\end{abstract}

\section{Introduction}

Genetic and epigenetic changes play an extremely large role in the etiology of cancer. ${ }^{1}$ Cancer is usually a disorder of aged individuals and uncommon in children. If cancer occurs in children this suggests an increased susceptibility to develop cancer. $^{2}$ Consequently, cancer in children will be frequently caused by a genetic change (mutation) and thus can be inherited. There are numerous examples of cancers occurring within families. ${ }^{3}$ Mutations in the same gene can occur both in inherited tumors (germline mutations) and in sporadic tumors (somatic mutations). ${ }^{4}$ Well-known examples of this are sporadic basal cell carcinoma and Gorlin syndrome (GS), or sporadic meningioma and neurofibromatosis type 2 (NF2).

received

August 19, 2013

accepted after revision

November 27, 2013

published online

March 10, 2014

In patients with inherited mutations of genes that can cause cancer, the inherited mutation itself is not sufficient to cause cancer: cells from such patients need to acquire one or more further mutations (Knudson two-hit theory). ${ }^{5,6}$ Not everyone will acquire such a second mutation, so not everyone who inherits a mutation in a cancer gene will indeed develop cancer. In hereditary tumor disorders, patients can develop multiple primary tumors as the second hit can occur independently at different loci. Furthermore, as children with a hereditary predisposition already have the first hit at conception, they are usually younger developing a tumor compared with their sporadic counterparts caused by acquired somatic mutations. ${ }^{7}$

(c) 2014 Georg Thieme Verlag KG Stuttgart · New York
DOI http://dx.doi.org/ 10.1055/s-0034-1368116. ISSN $0174-304 X$. 


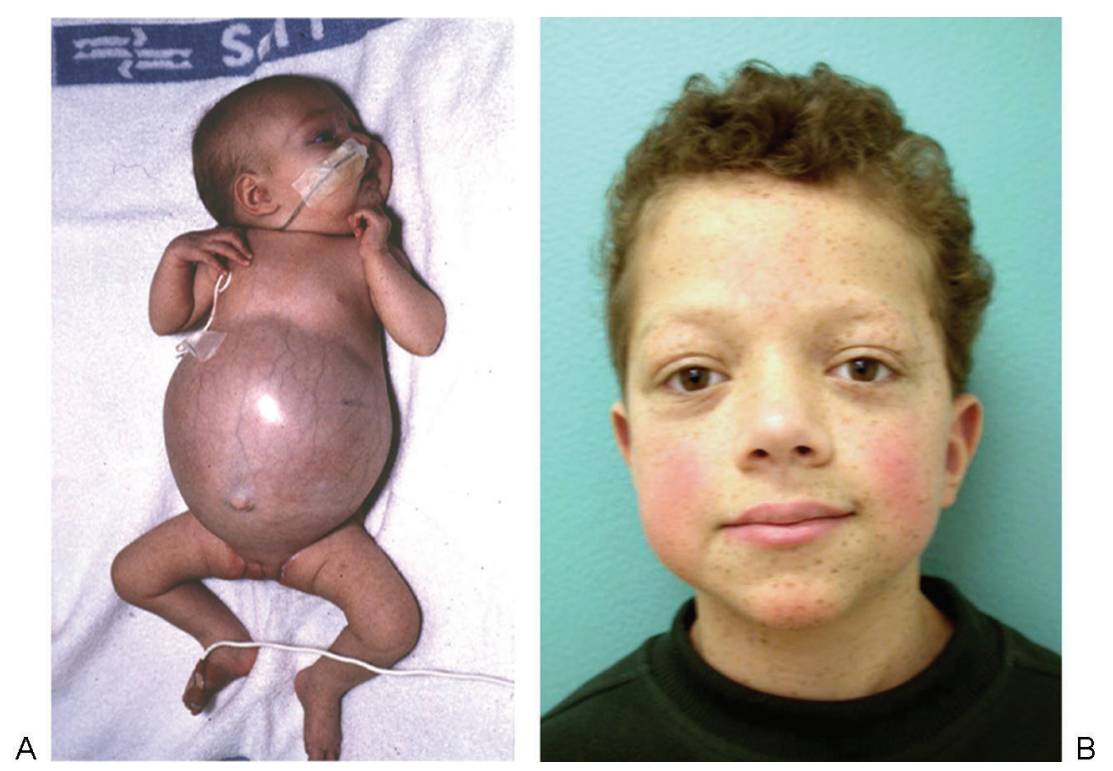

Fig. 1 Child with neuroblastoma and LEOPARD syndrome. Because of the enormous swelling of the belly in the acute stage as a consequence of the neuroblastoma (A), the LEOPARD syndrome was not diagnosed at that time. Only after treatment for the neuroblastoma and recovery, the phenotype became clear and child was diagnosed to have LEOPARD syndrome (B). ${ }^{12}$

Genes and their corresponding proteins have (almost) invariably a dual function, one prenatally and one postnatally: A gene that steers the formation of an organ or body part (developmental gene) during embryogenesis, frequently becomes a gene that is involved in growth regulation after birth. ${ }^{4}$ Subsequently, we may expect that a mutated developmental gene causes an unusual phenotype or syndrome prenatally and may go along with an increased risk for the same individual to develop cancer postnatally. Indeed, children with congenital anomalies and syndromes have a higher risk to develop cancer, ${ }^{8}$ including tumors of the central nervous system (CNS). ${ }^{9,10}$ In addition, children with cancer have more morphological abnormalities, ${ }^{11}$ malformations, ${ }^{12}$ and more syndromes as well. ${ }^{13}$ The recognition of syndromes in children is often problematic as it needs proper examination by a clinical geneticist or a pediatrician skilled in clinical morphology and obtaining a detailed family history to detect this (-Fig. 1). ${ }^{14}$

Like other types of cancer, tumors of the CNS usually occur in adults. Only 7\% of CNS tumors occur in children. ${ }^{15}$ CNS tumors are relatively frequent compared with other types of cancer in children, and comprise approximately $25 \%$ of all childhood tumors. ${ }^{16}$ Some CNS tumors in children (embryonal CNS tumors as medulloblastoma and ependymoma, and also pilocytic astrocytoma) are linked to factors contributing to brain growth early in (postnatal) life, ${ }^{17}$ as these tumors occur less frequent with increasing age. ${ }^{15}$ In contrast, during adolescence, the incidence of intracranial germ cell tumors peaks suggesting that puberty itself either initiates or drives their growth. ${ }^{17}$ The increased risk for a child with malformations to develop a tumor ${ }^{8}$ is reflected in the increased risk for children with CNS malformations to develop CNS tumors. ${ }^{10}$ For example, closing defects of the neural tube (including occult spinal dysraphism) are known to have a higher co- occurrence of both intracranial and intraspinal lipoma and teratoma. ${ }^{18-20}$ Furthermore, the same pathway seems to be aberrantly activated in different disorders. For example, the SHH-PTCH-GLI pathway is involved in holoprosencephaly, Smith-Lemli-Opitz syndrome, pediatric medulloblastomas and GS (- Table 1). ${ }^{21}$ Recently, an overview of somatic mosaic mutations in neurodevelopmental and overgrowth syndromes was provided, and some of these genes (or pathways they act in) are also involved in tumor predisposition syndromes. $^{22}$

To our knowledge, no overall analysis has been published on the frequency of CNS tumors in children with a genetic syndrome or the occurrence of syndromes in children with a CNS tumor. Here, we provide a review of the various CNS tumors that occur in children with syndromes and of the syndromes that occur in children with brain tumors. With this, we aim to facilitate recognition of syndromes in children with a brain tumor and early diagnosis of brain tumors in children with syndromes. First, we address from a tumor perspective, which syndromes may be associated with the specific CNS tumor type (-Table $\mathbf{1}$ ). Next, we concentrate on well-characterized hereditary syndromes that result from germline mutations in highpenetrance genes and predispose to CNS tumor development (-Table 2). We do not provide data on brain tumors caused by somatic mutations. Because of limited space we have not aimed to be exhaustive for each syndrome, but have put emphasis on the most frequent (morphologic) manifestations and most prevalent syndromes. We acknowledge that most pediatricians and neurologists may not be familiar with the terminology used in clinical genetics and dysmorphology and have provided short descriptions of the main terms used in -Table 3. 


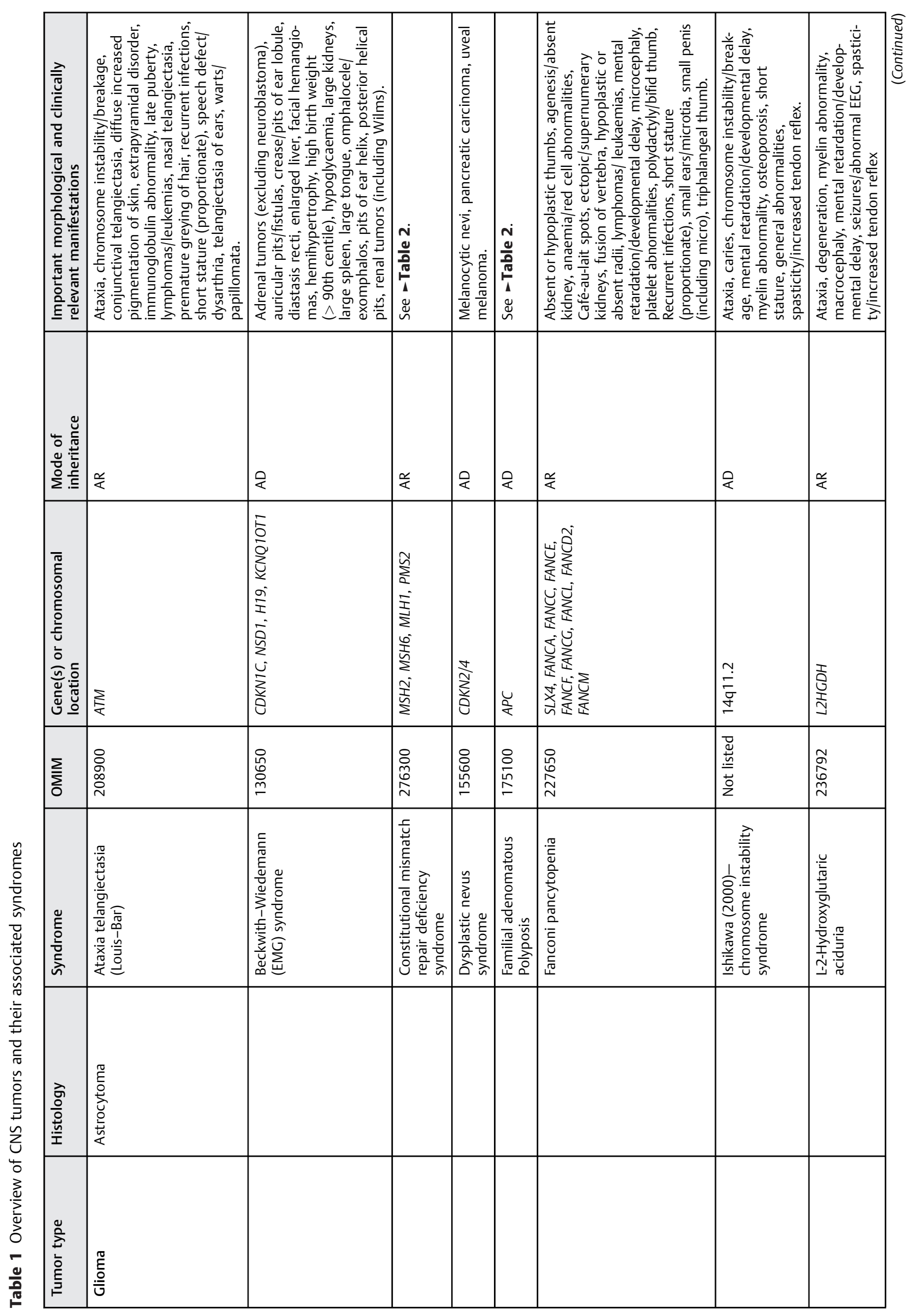




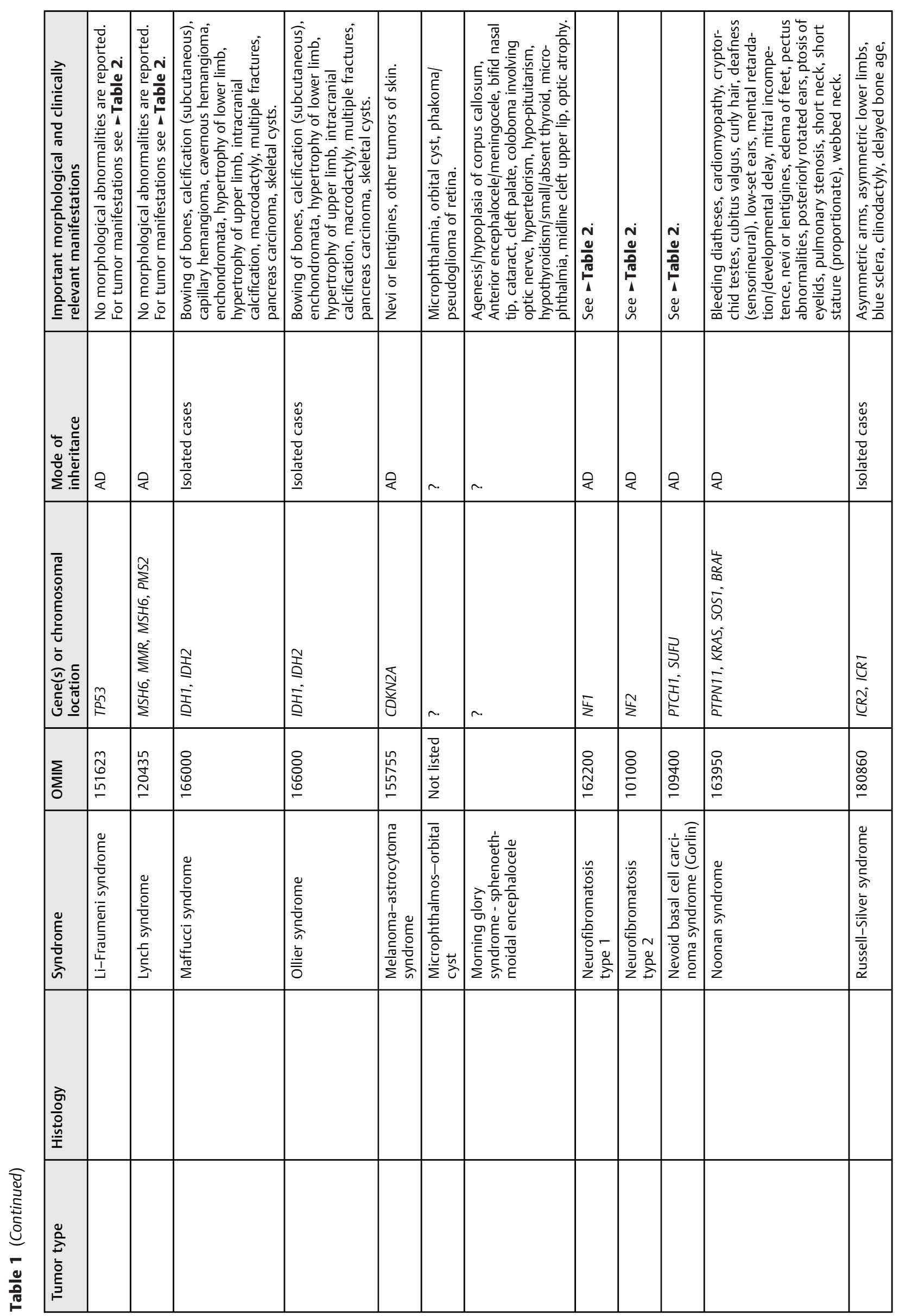




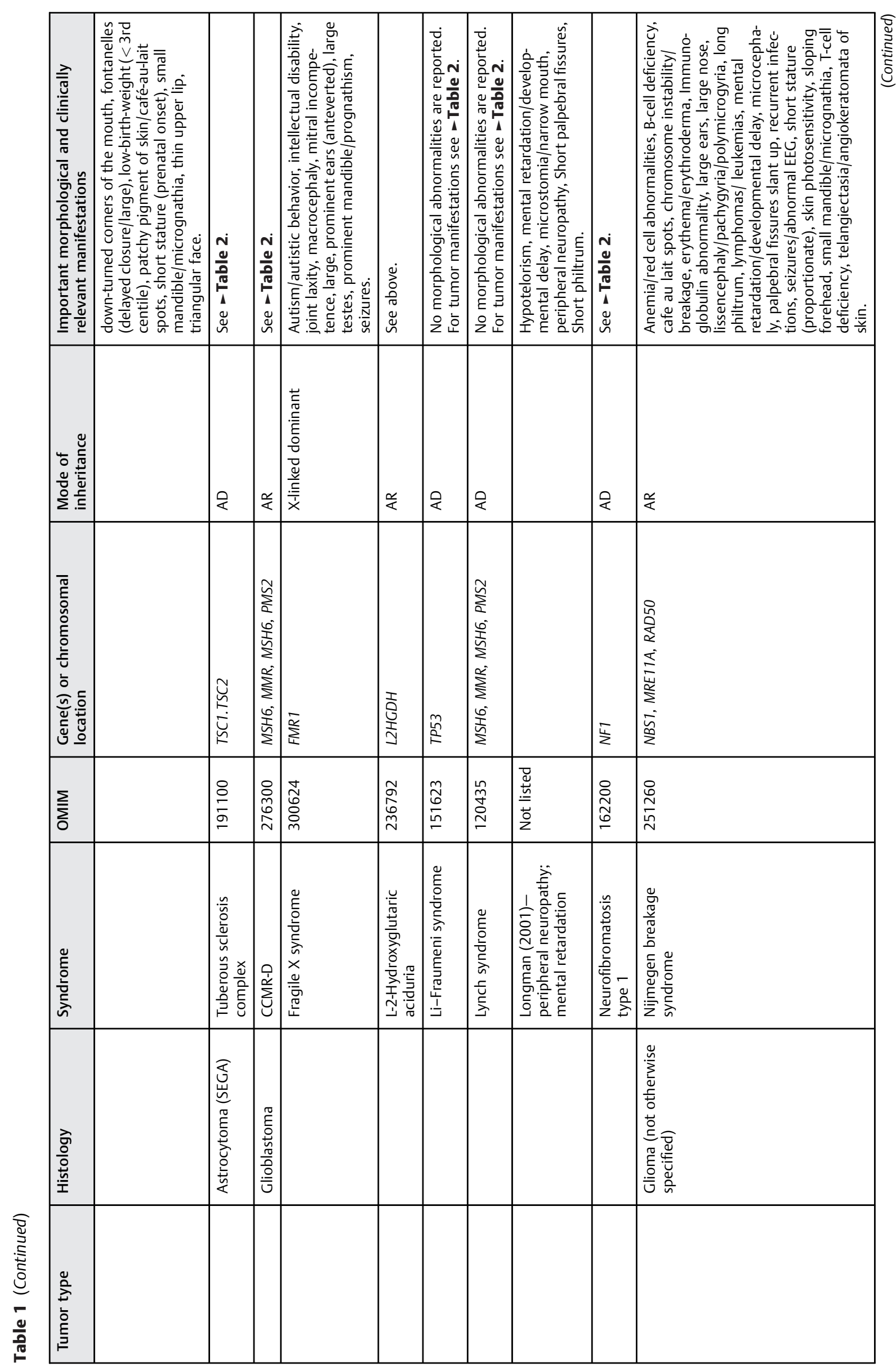




\begin{tabular}{|c|c|c|c|c|c|c|c|c|c|c|c|c|c|c|}
\hline 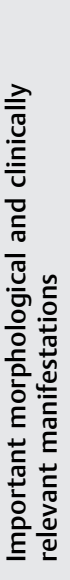 & 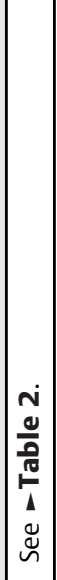 & 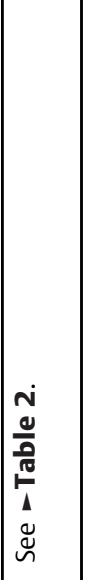 & 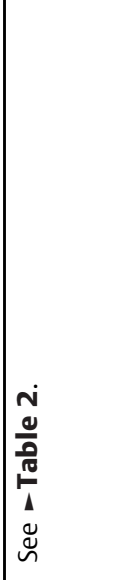 & 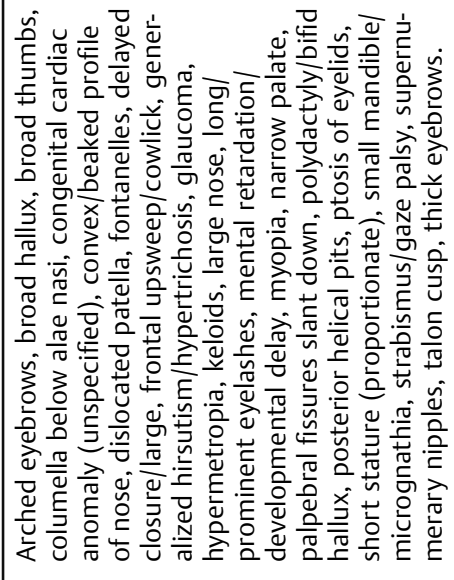 & 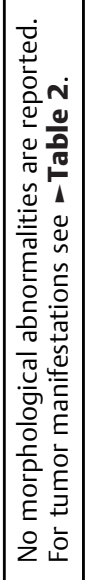 & 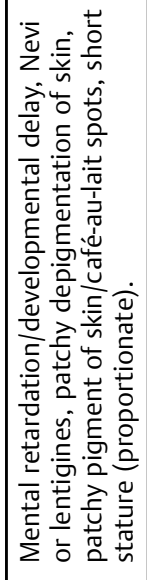 & 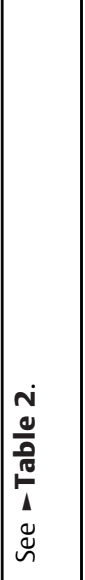 & 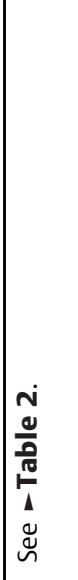 & 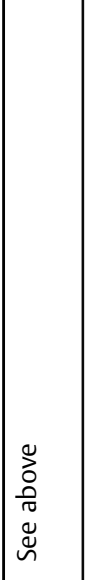 & 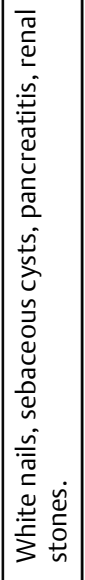 & 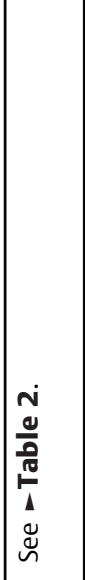 & 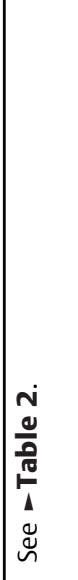 & 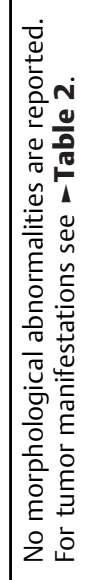 & 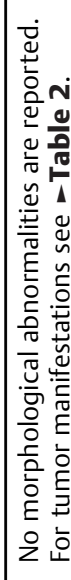 \\
\hline 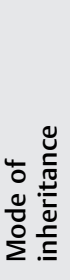 & $\stackrel{\stackrel{\alpha}{<}}{2}$ & \& & & 㝏 & 安 & 安 & 安 & 安 & 妾 & 安 & 安 & 是 & 是 & 是 \\
\hline 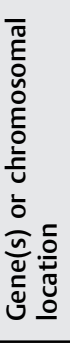 & 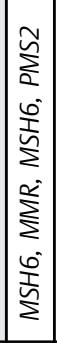 & 产 & 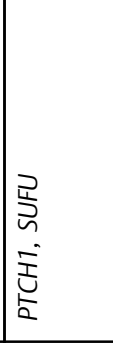 & 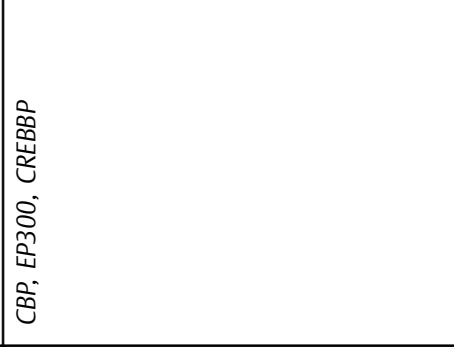 & 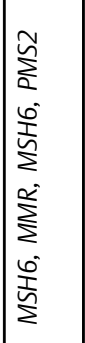 & $\sim$. & $\frac{0}{4}$ & 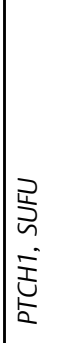 & 咅 & & 玄 & $\frac{N}{2}$ & 㞐 & 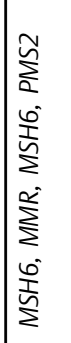 \\
\hline 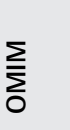 & 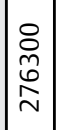 & $\begin{array}{l}\stackrel{8}{0} \\
\frac{1}{n} \\
=\end{array}$ & $\begin{array}{l}\text { 우 } \\
\text { के } \\
\stackrel{\circ}{-}\end{array}$ & \begin{tabular}{l}
$q$ \\
\multirow{1}{0}{} \\
$\infty$ \\
$\infty$ \\
-
\end{tabular} & 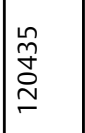 & 总 & $\begin{array}{l}\stackrel{8}{\frac{1}{2}} \\
\stackrel{2}{=}\end{array}$ & 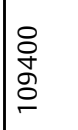 & $\mid \begin{array}{l}\tilde{\sigma} \\
\hat{\sigma} \\
\tilde{N}\end{array}$ & 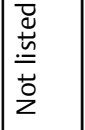 & $\begin{array}{l}\stackrel{\overbrace{}}{\grave{N}} \\
\text { } \\
-\end{array}$ & $\mid \begin{array}{l}\circ \\
\stackrel{0}{\circ} \\
-\end{array}$ & $\begin{array}{l}\tilde{\widetilde{\omega}} \\
\stackrel{\tilde{n}}{\llcorner}\end{array}$ & $\underset{\stackrel{\sim}{\tilde{N}}}{\stackrel{\sim}{\tilde{N}}}$ \\
\hline 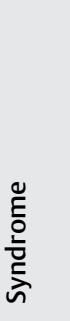 & 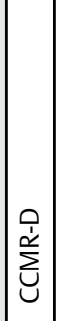 & 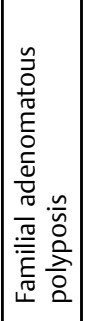 & 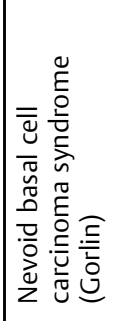 & 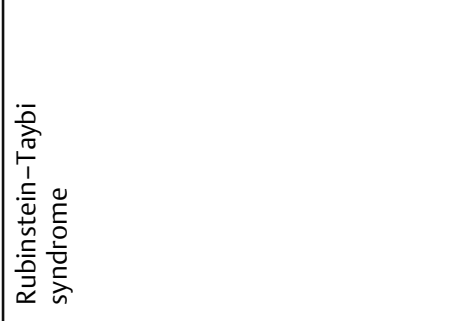 & 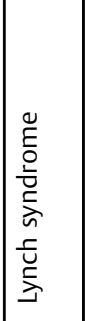 & 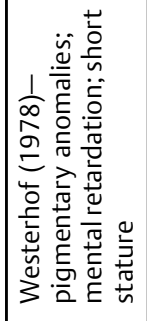 & 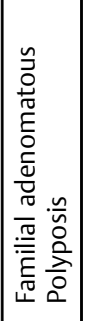 & 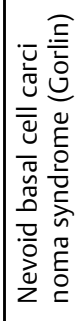 & 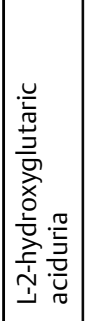 & 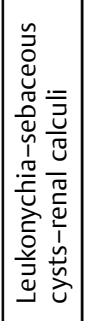 & 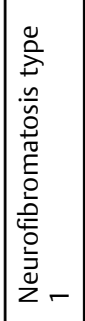 & 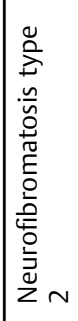 & 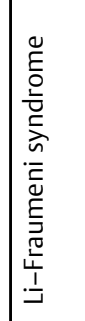 & 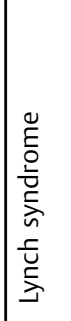 \\
\hline 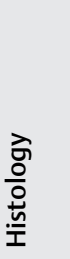 & 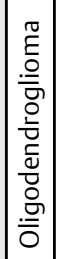 & & & & & & 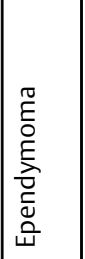 & & & & & & & \\
\hline 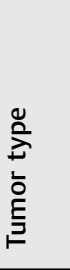 & & & & & & & 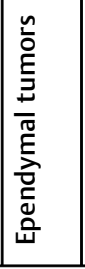 & & & & & & & \\
\hline
\end{tabular}




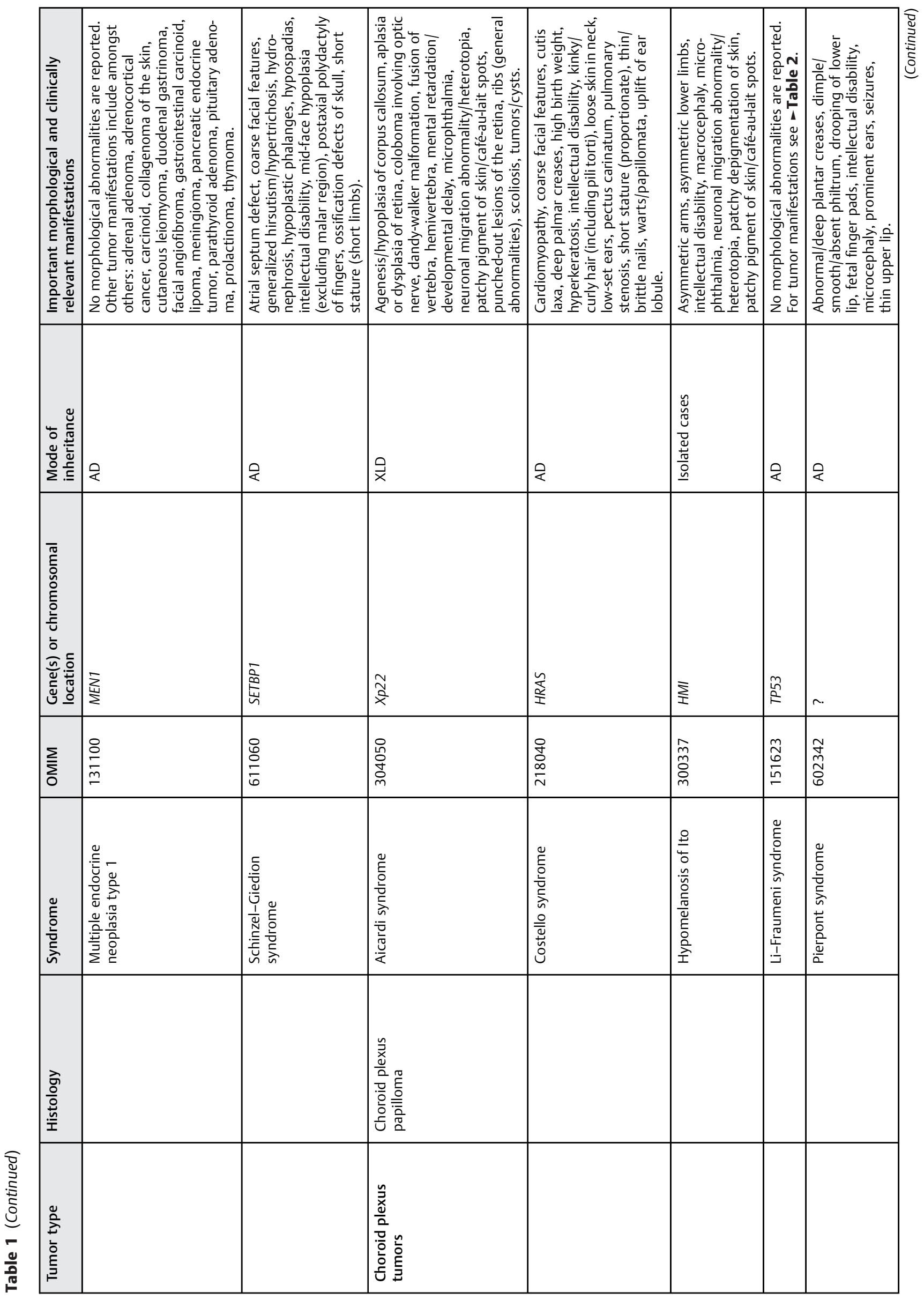




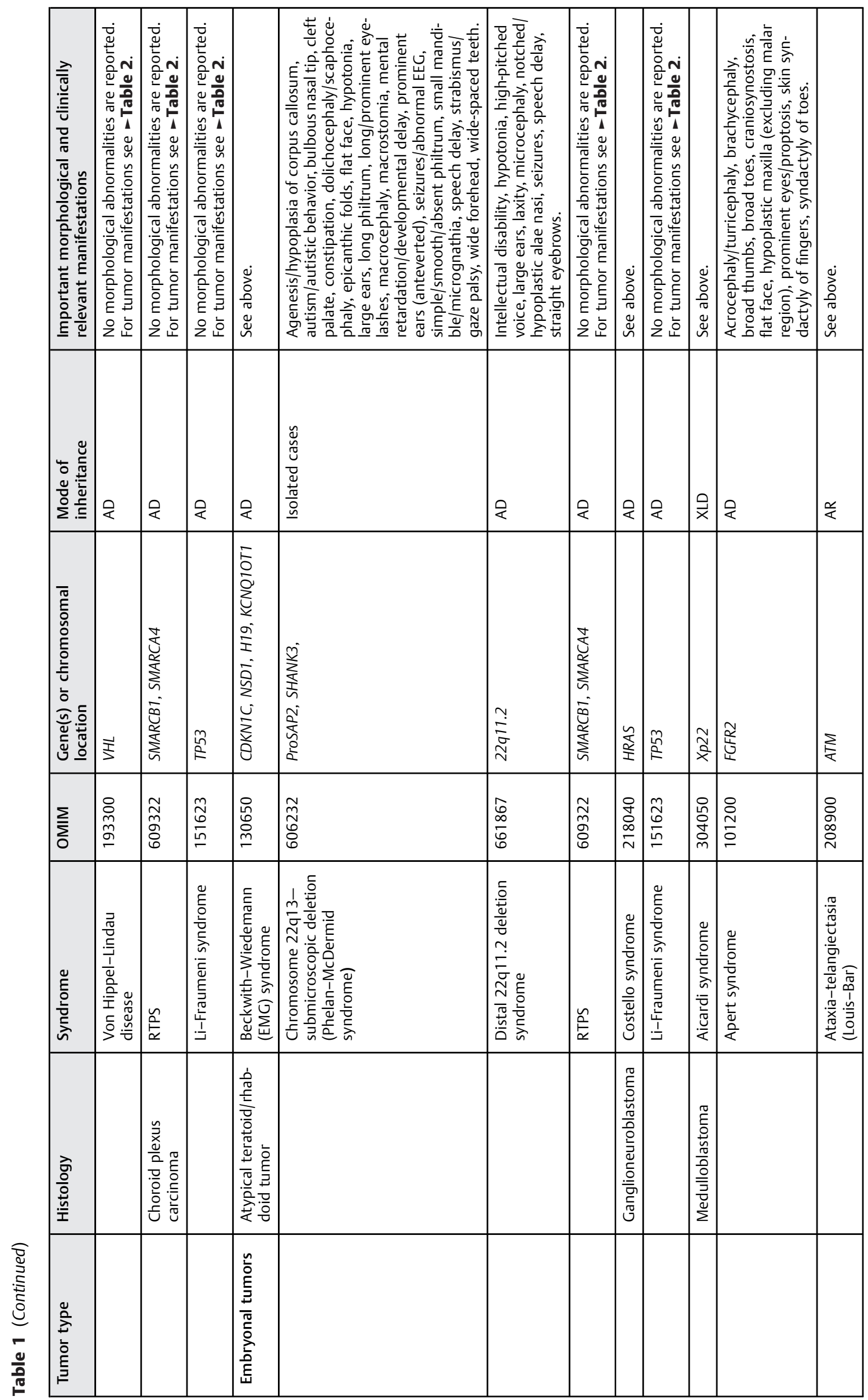




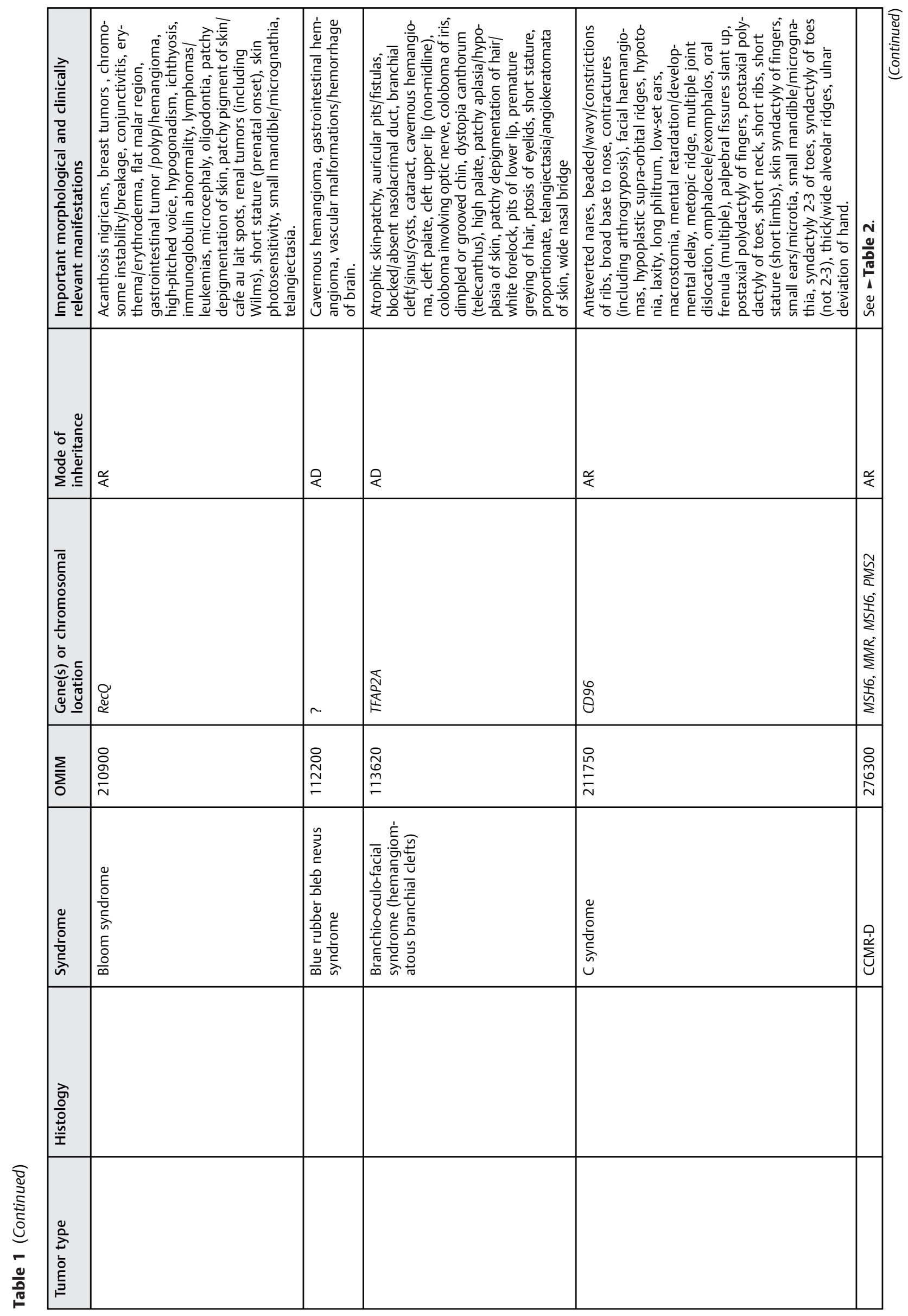




\begin{tabular}{|c|c|c|c|c|c|c|c|c|}
\hline 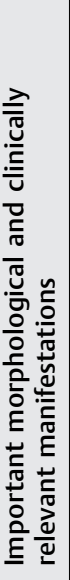 & 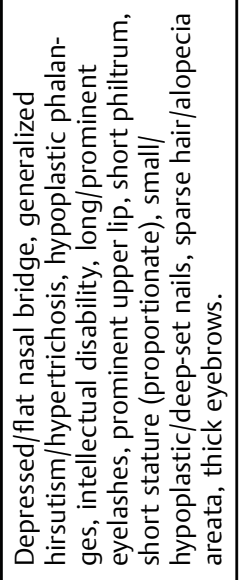 & 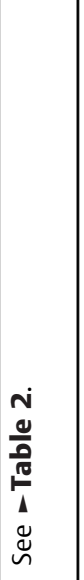 & 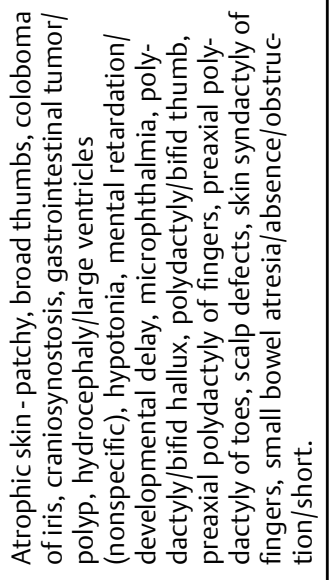 & 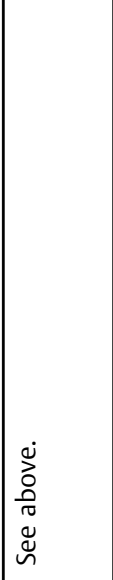 & 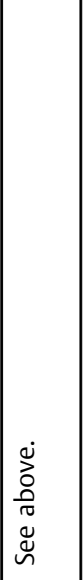 & 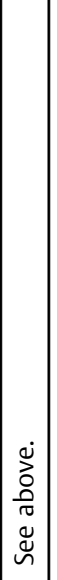 & 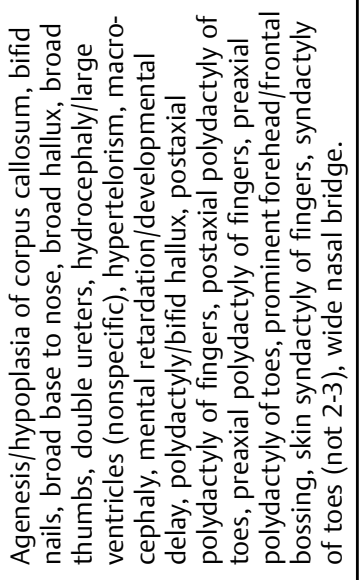 & 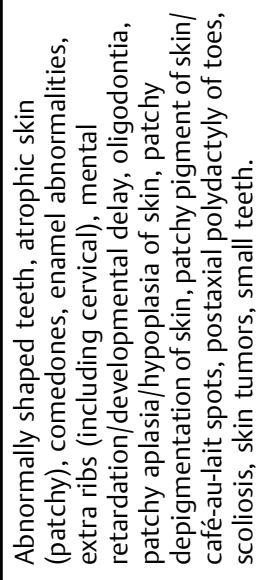 \\
\hline 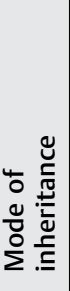 & $\stackrel{⿱}{<}$ & 安 & 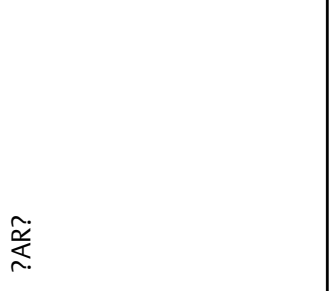 & $\stackrel{\stackrel{\alpha}{<}}{<}$ & 定 & 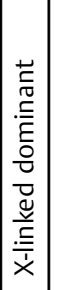 & \& & r. \\
\hline 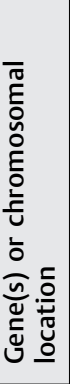 & 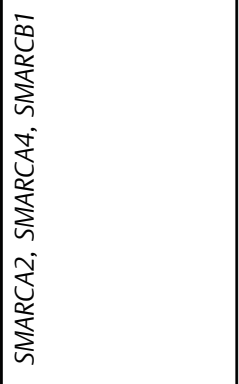 & 兽 & r. & 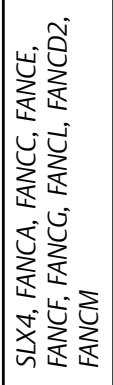 & $\grave{⿱ 亠 乂}$ & $\sum_{\underline{L}}^{\bar{\alpha}}$ & $\stackrel{m}{\cup}$ & n. \\
\hline$\sum_{0}$ & 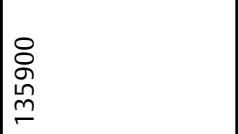 & 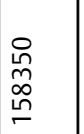 & $\begin{array}{l}\frac{1}{0} \\
\frac{0}{0}\end{array}$ & $\begin{array}{l}\text { 오 } \\
\stackrel{0}{N} \\
\text { N }\end{array}$ & 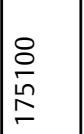 & 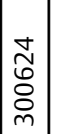 & 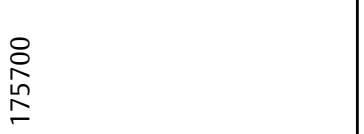 & $\mid \begin{array}{l}\underline{\underline{u}} \\
\underline{\underline{\underline{w}}} \\
\underline{\underline{0}}\end{array}$ \\
\hline 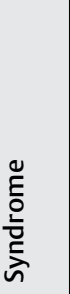 & 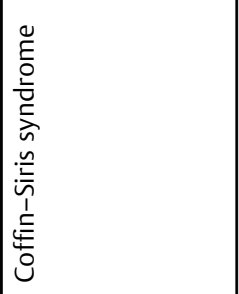 & 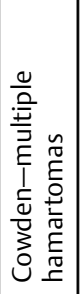 & 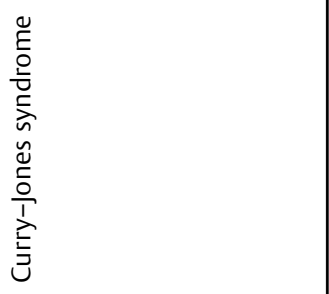 & 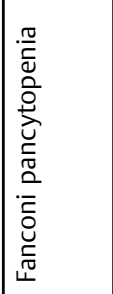 & 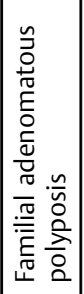 & 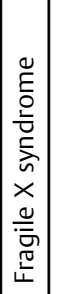 & 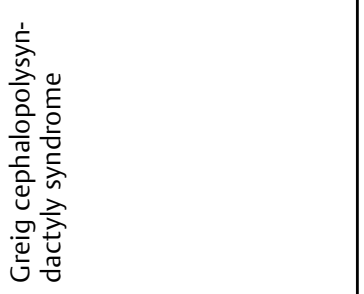 & 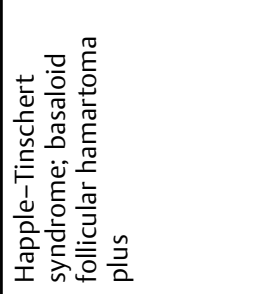 \\
\hline$\frac{\text { वे }}{\frac{0}{0}}$ & & & & & & & & \\
\hline 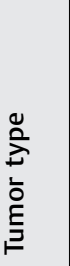 & & & & & & & & \\
\hline
\end{tabular}




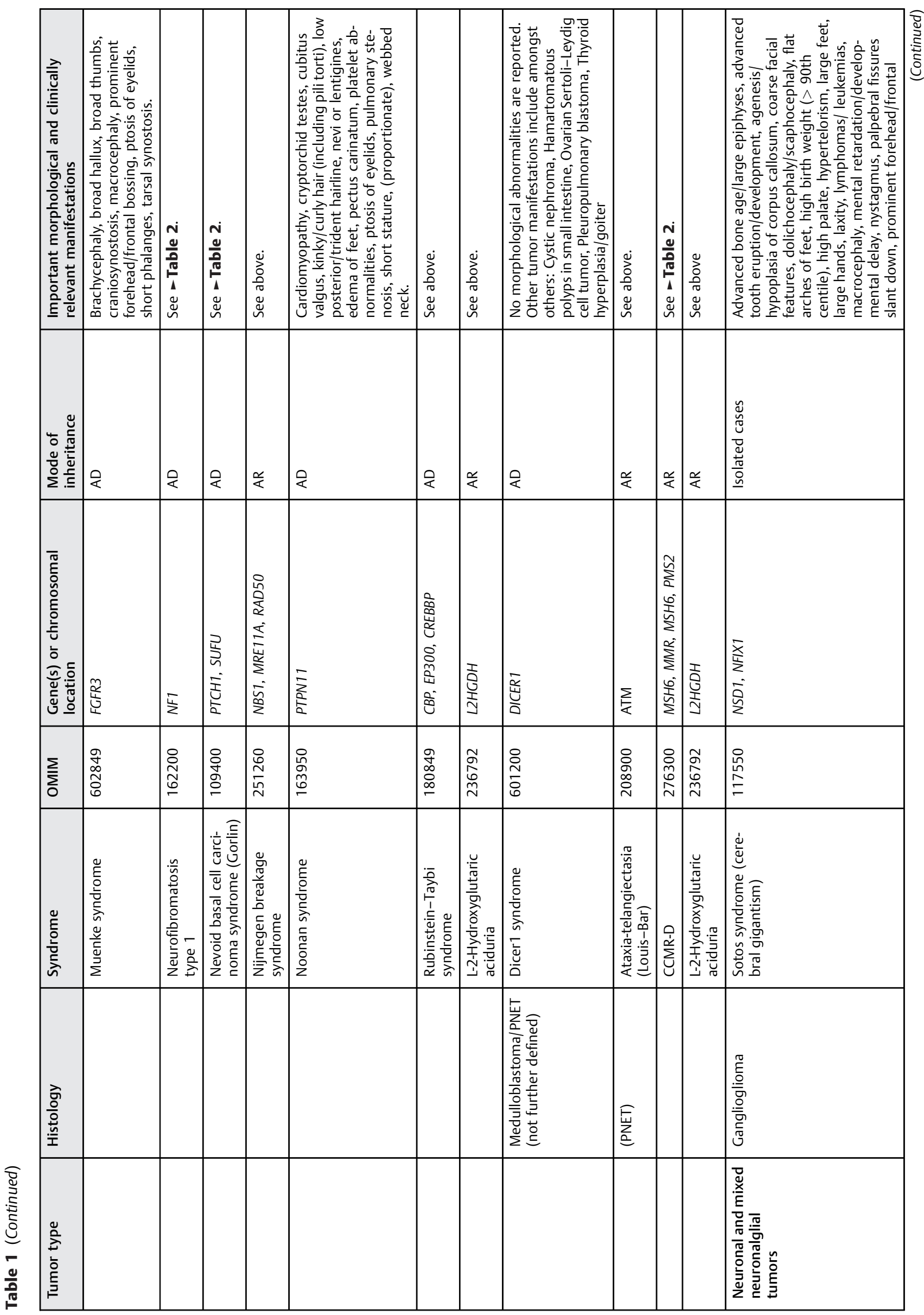




\begin{tabular}{|c|c|c|c|c|c|c|c|c|c|c|c|c|c|}
\hline 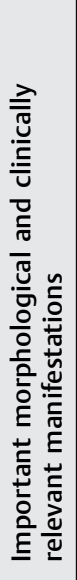 & 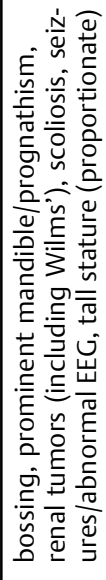 & $\mid$ & 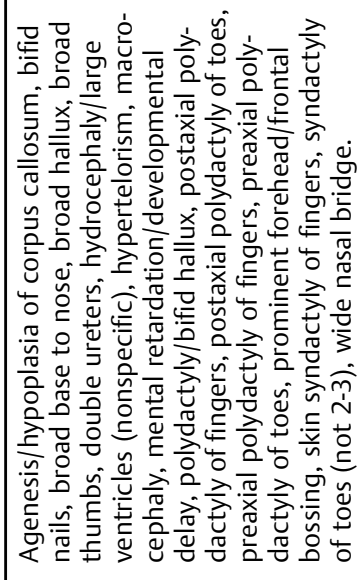 & 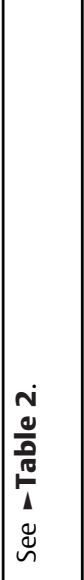 & 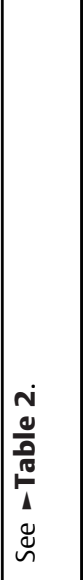 & 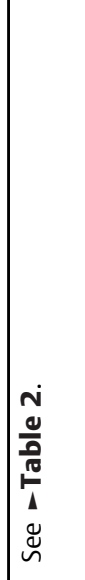 & 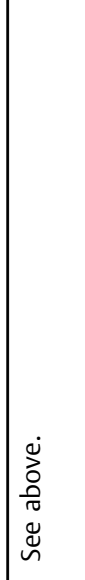 & 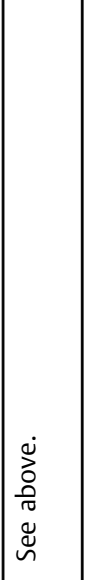 & 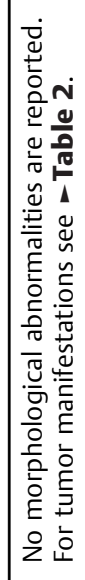 & 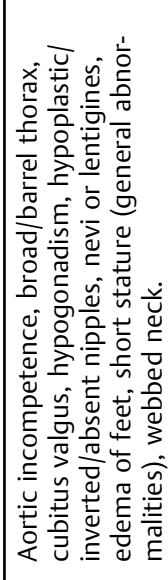 & 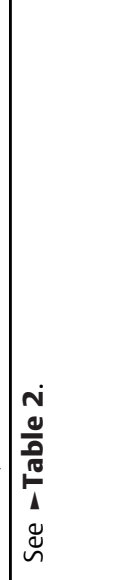 & 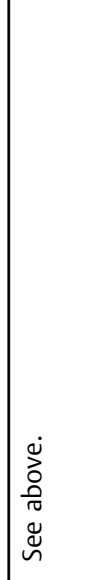 & 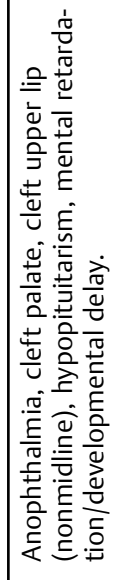 \\
\hline 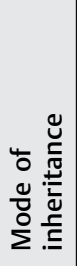 & & 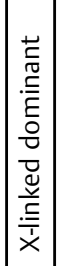 & 是 & 是 & 定 & 安 & 妾 & 定 & 是 & 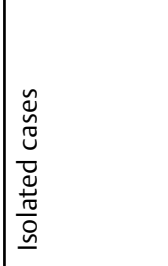 & 是 & $\overrightarrow{\vec{x}}$ & . \\
\hline 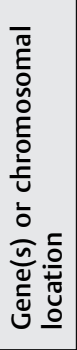 & & 帝 & $\stackrel{m}{\mathcal{G}}$ & $\frac{4}{2}$ & $\frac{N}{2}$ & $\begin{array}{l}\frac{3}{2} \\
\frac{1}{4} \\
\vdots \\
\vdots \\
\frac{1}{2} \\
\frac{1}{2}\end{array}$ & 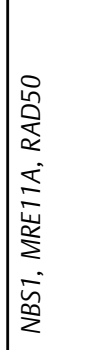 & 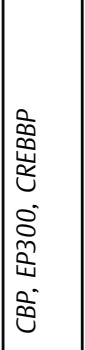 & $\begin{array}{l}\overline{0} \\
\bar{s} \\
\tilde{\alpha} \\
\bar{n}\end{array}$ & $\begin{array}{l}\stackrel{0}{\times} \\
\stackrel{\text { f́ }}{ }\end{array}$ & $\overrightarrow{\mid}$ & $\underset{\tilde{\hat{x}}}{\tilde{\hat{x}}}$ & . \\
\hline$\sum_{0}^{\sum}$ & & 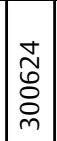 & 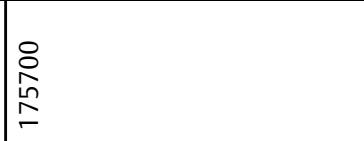 & 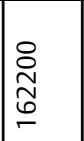 & $\begin{array}{l}\circ \\
\circ \\
\\
\end{array}$ & 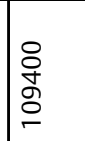 & $\begin{array}{l}\stackrel{0}{0} \\
\stackrel{N}{\mathfrak{N}} \\
\stackrel{1}{N}\end{array}$ & $\begin{array}{l}g \\
\stackrel{g}{0} \\
\infty \\
\infty \\
-\end{array}$ & 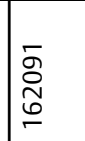 & 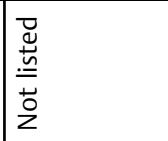 & $\begin{array}{l}\stackrel{8}{ } \\
\tilde{m} \\
\tilde{\sigma} \\
\underline{n}\end{array}$ & 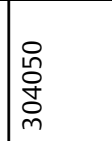 & 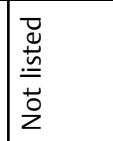 \\
\hline 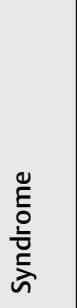 & & 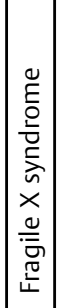 & 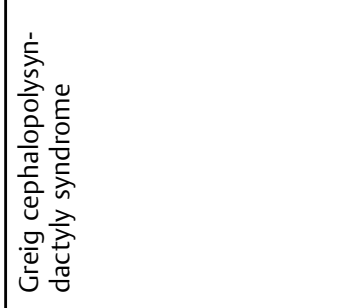 & 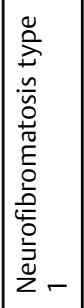 & 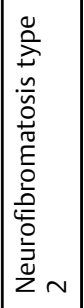 & 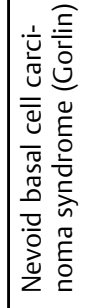 & 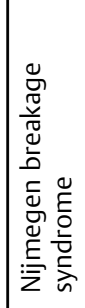 & 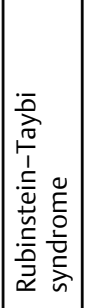 & 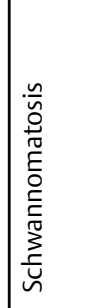 & 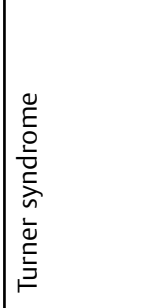 & 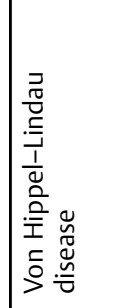 & 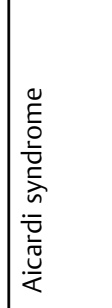 & 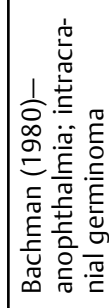 \\
\hline $\begin{array}{l}\text { वे } \\
\frac{0}{0} \\
\frac{\hat{m}}{I}\end{array}$ & & & 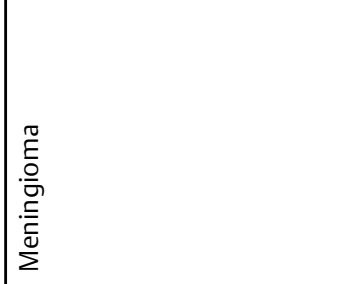 & & & & & & & & 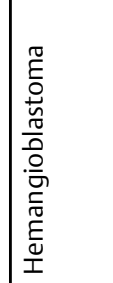 & 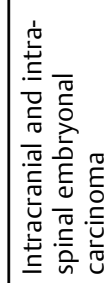 & 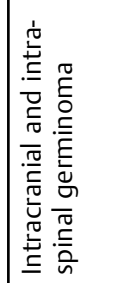 \\
\hline 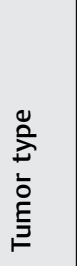 & & & 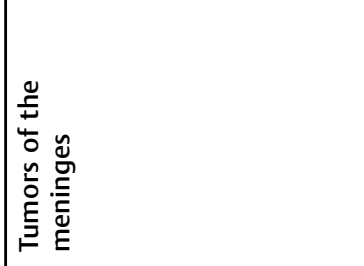 & & & & & & & & 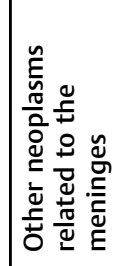 & 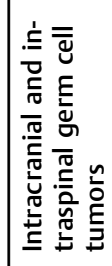 & \\
\hline
\end{tabular}




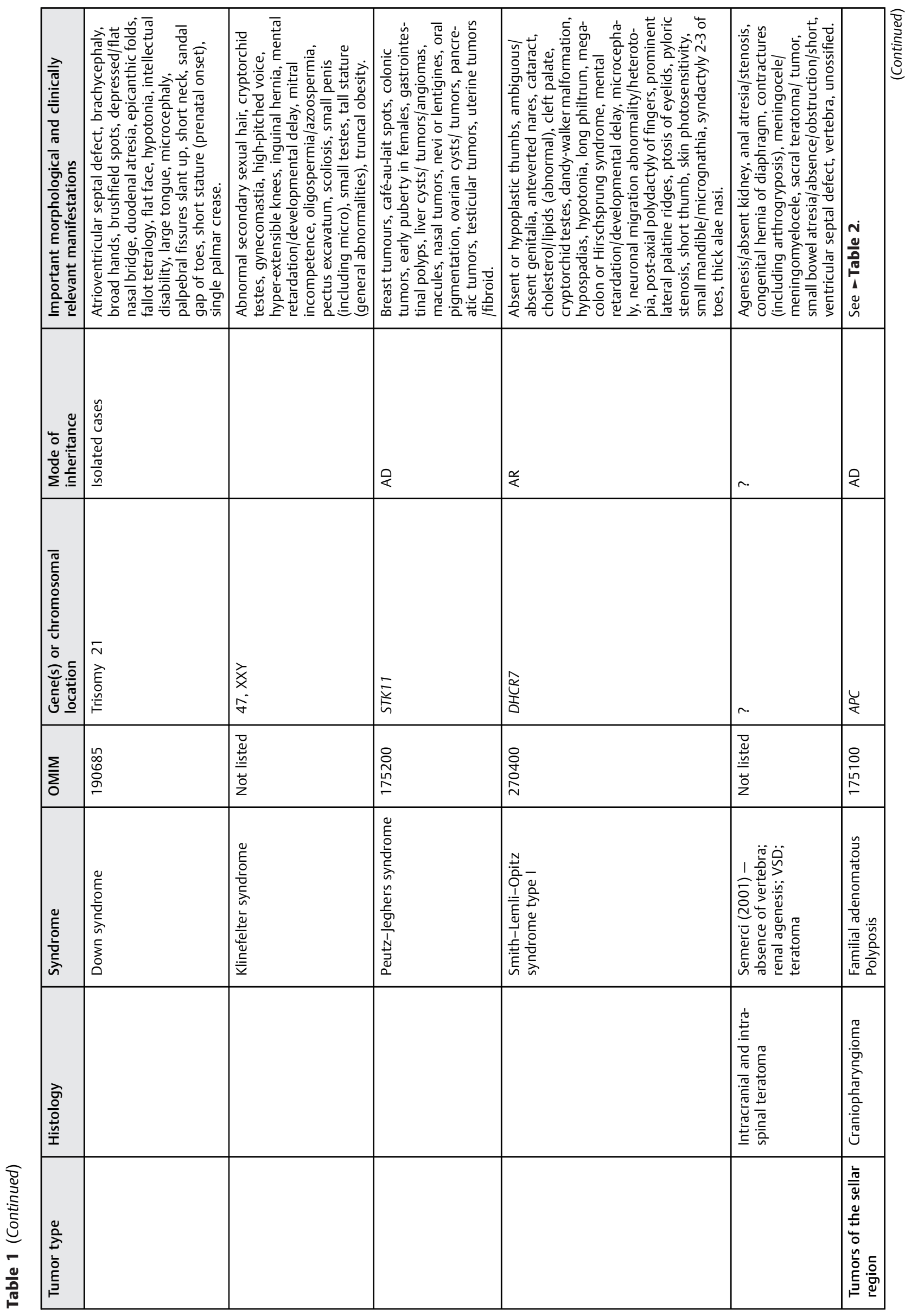



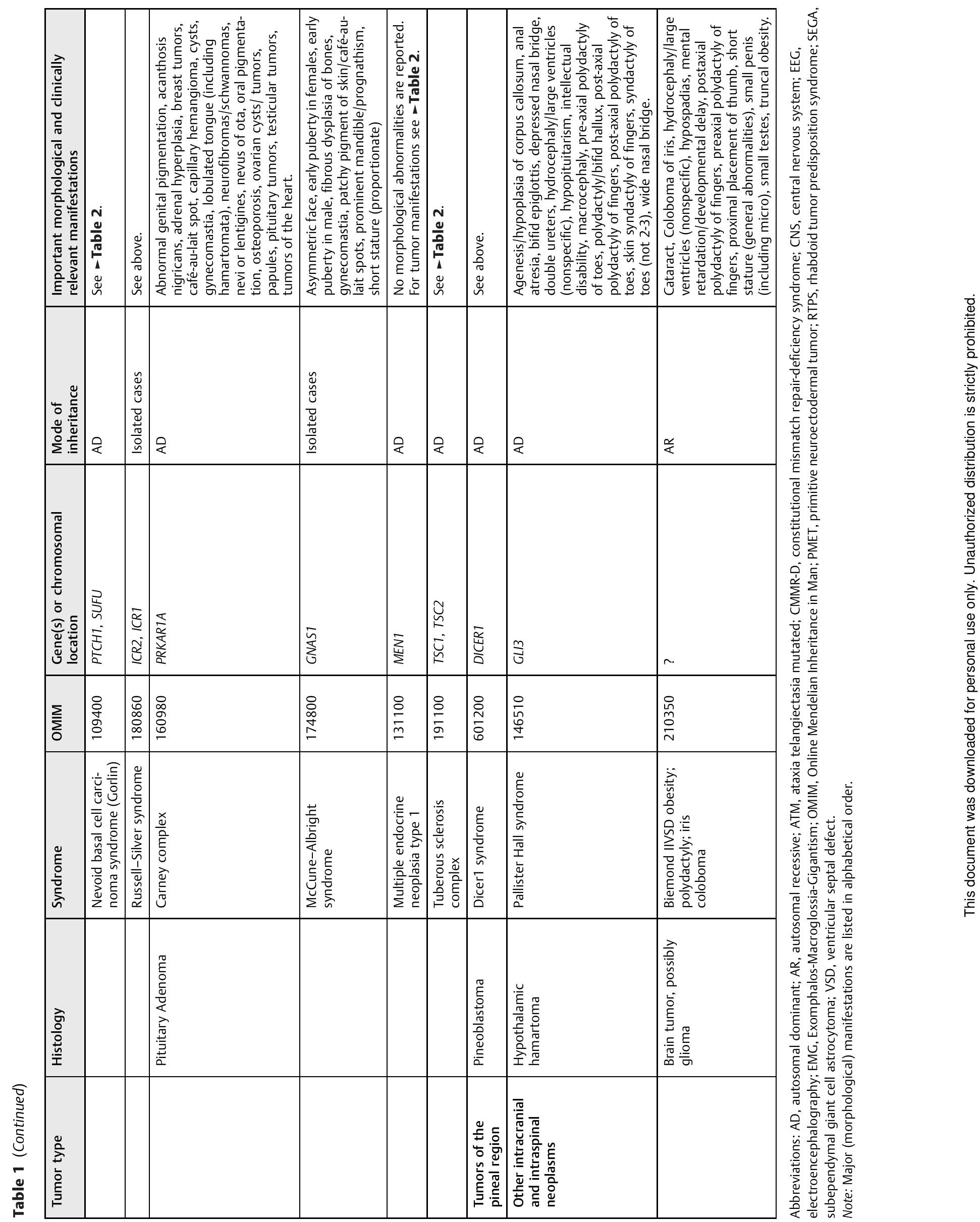


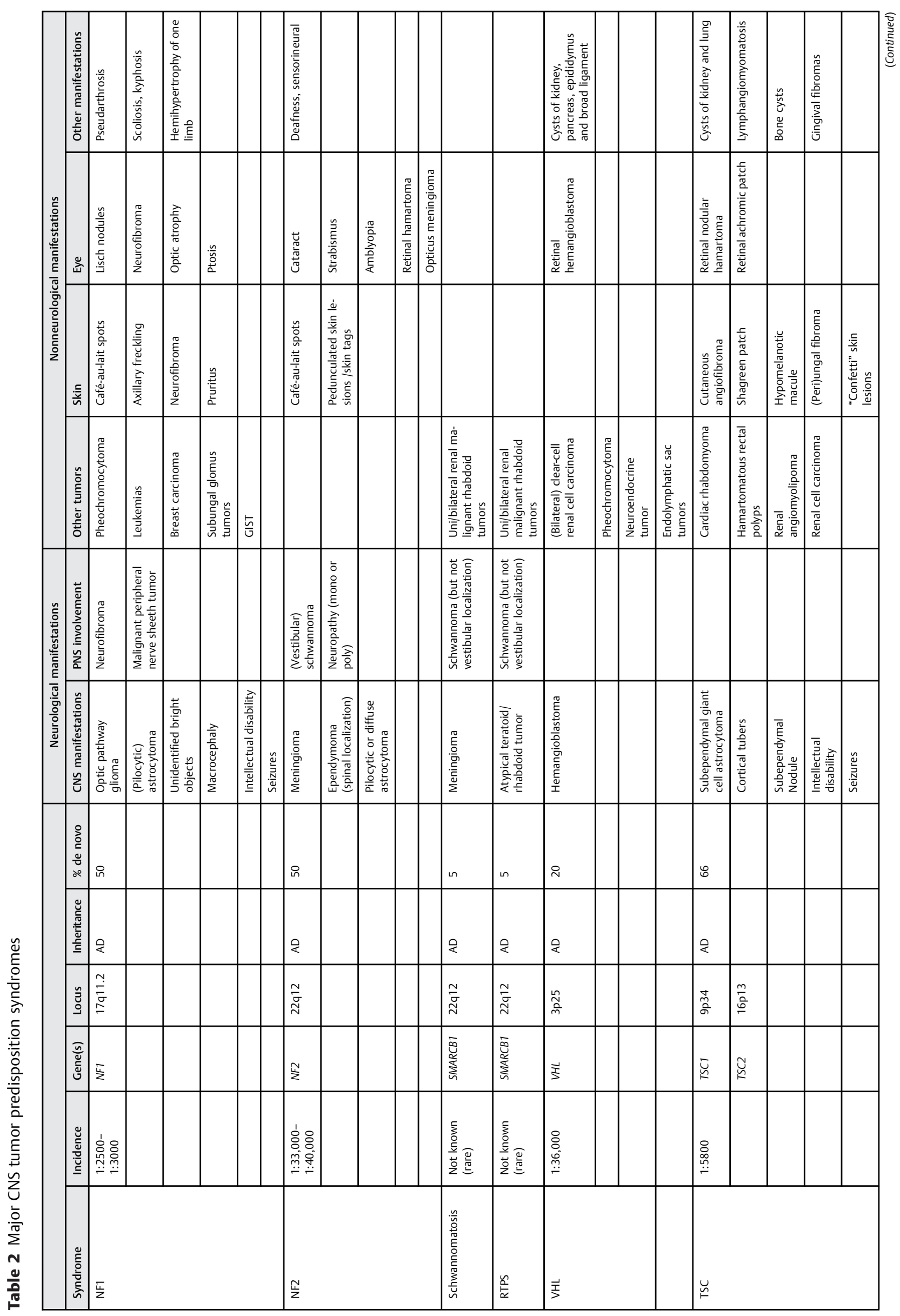




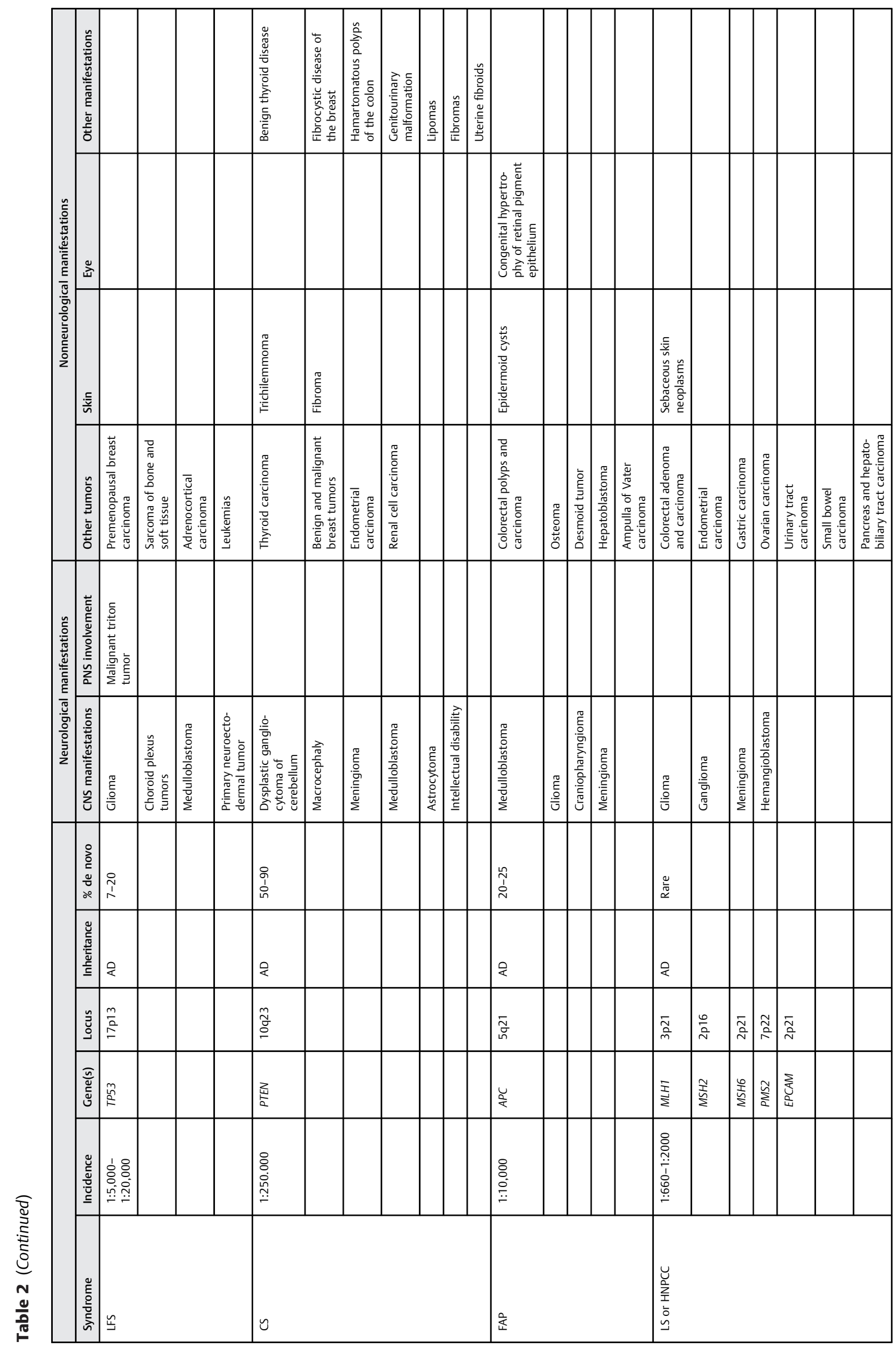




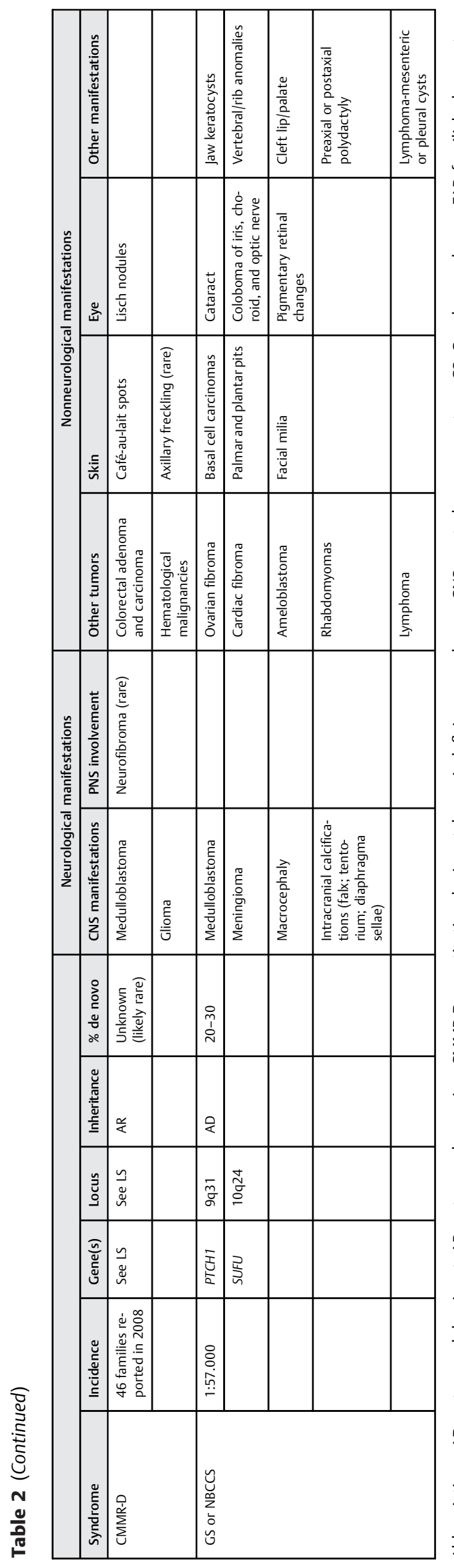

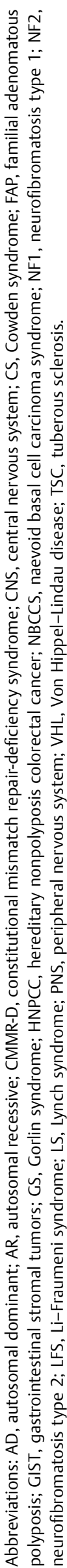

\section{Methodology}

We used four sources to obtain data for the overview: the Winter-Baraitser Dysmorphology Database (WBDD) ${ }^{23}$; the book Gorlin's Syndromes of the Head and Neck ${ }^{8}$; the WHO Classification of Tumours of the Central Nervous System ${ }^{24}$; and literature searches using PubMed. A detailed description of the methodology to obtain the data from the first two sources is available elsewhere. ${ }^{25}$ In short, search terms derived from the diagnostic groups of the International Classification of Childhood Cancer $^{26}$ were checked in all syndromes from the WBDD and the Gorlin text. This search was focused on syndromes with morphological abnormalities in which malignant brain tumors occur in infants and/or children. This overview was supplemented with syndromes with either benign CNS tumors (e.g., meningioma) and/or tumor predisposition syndromes without unusual morphology (e.g., Li-Fraumeni Syndrome [LFS]). Data for this was derived from the WHO Classification of Tumours of the Central Nervous System, ${ }^{24}$ Familial Cancer Database (http://www.facd.info), Gene Reviews (http://www.ncbi.nlm.nih.gov/books/NBK1116/), and directed searches for each of the CNS tumor types in this overview in PubMed (http://www.ncbi.nlm.nih.gov/pubmed). The CNS tumor types are named according to the WHO Classification of Tumours of the Central Nervous System. ${ }^{24}$ To decrease the number of citations, we do not refer to original references but to the above main sources.

All syndromes resulting from our searches, in which at least once a CNS tumor was reported, have been included in this overview. In infrequent entities, it may remain uncertain whether the co-occurrence of a tumor is explainable by chance or has a true causal relation. Therefore, the present overview (-Table 1) may contain overestimations of associations between CNS tumors and syndromes. We have accepted this as in our opinion it is preferable to report all known possible associations instead of exclusion of true but presently uncertain associations.

In - Table 1, only major (morphologic) manifestations are reported. Therefore, other manifestations that may be seen in children do not exclude the presence of either one of the mentioned syndromes.

\section{Results}

\section{General}

- Table 1 contains all major brain tumor types occurring in children and the various syndromes that have been reported to be associated with these tumors. - Table 2 contains a short overview of all major tumor predisposition syndromes. The most frequent entities with a high chance to develop a brain tumor are summarized in - Table $\mathbf{2}$. We provide short descriptions restricted to major presentations and co-occurring brain tumor of each of the entities below.

\section{Neurofibromatosis Type 1}

The first clinical suspicion of NF1 (Recklinghausen disease) should be raised when in an infant or child multiple café-aulait spots are noticed. NF1 may not be obvious immediately: 
Table 3 Genetic vocabulary

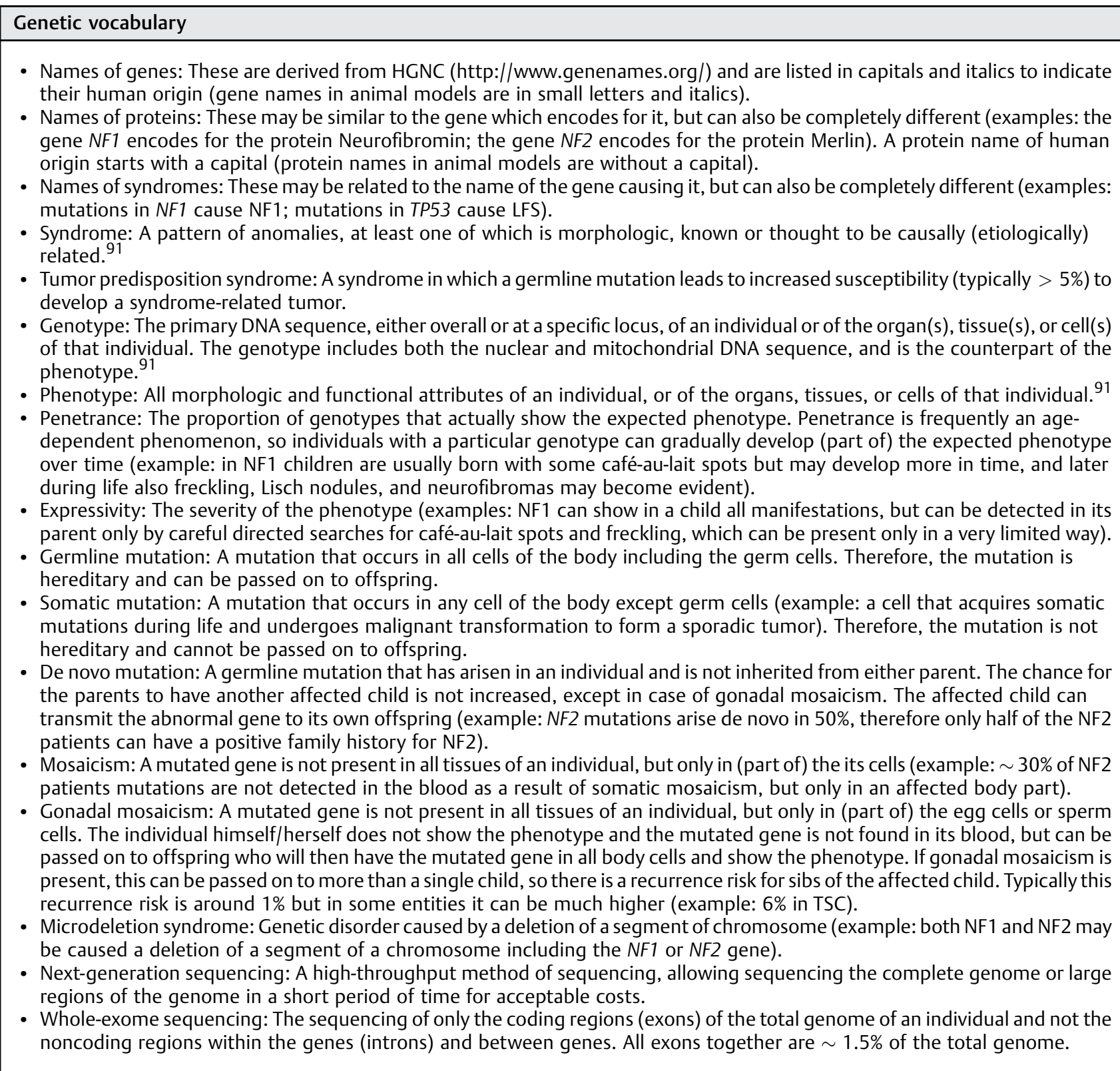

Abbreviations: HGNC, HUGO Gene Nomenclature Committee; LFS, Li-Fraumeni syndrome; NF1, neurofibromatosis type 1; NF2, neurofibromatosis type 2; TSC, tuberous sclerosis complex.

axillary or inguinal freckling appears during the first 5 years of age. Iris hamartoma (Lisch nodules) generally appear just after and are found only if specifically looked for at ophthalmological examination. Cutaneous neurofibromas are seen in most patients starting in puberty. ${ }^{27}$ NF1 mutations are highly penetrant, but expression is extremely variable. Approximately $15 \%$ of patients with NF1 develop a CNS tumor. Particularly, optic nerve astrocytoma is common, which only requires treatment if symptoms develop or progression occurs. Other gliomas seen in NF1 are pilocytic and diffuse astrocytomas (preferential localizations pons and cerebellum) and rarely glioblastoma. At T2-weighted magnetic resonance images (MRI) unidentified bright objects (UBO), previously wrongly tagged as hamartomas, can be noted in over $50 \%$ of NF1 patients. They are seemingly innocent and disappear with age. Neurofibromas are generally treated surgically if causing pain by nerve compression or for cosmetic reasons. Diffuse plexiform neurofibromas are generally hidden internally in close vicinity of organs, and can be difficult to detect and treat. Approximately $10 \%$ of NF1 patients develop malignant peripheral nerve sheath tumors (MPNST). Radical surgical resection is the mainstay of treatment of MPNST and adjuvant chemotherapy and/or radiotherapy should be considered. A limited (32\%) 5-year overall survival in the context of NF1 is seen. ${ }^{28,29}$ Also other, nonnervous system associated tumors and osseous and vascular 
abnormalities occur more often in NF1 patients. In NF1 patients, exposure to diagnostic and therapeutic radiation should be minimized to avoid the risk of radiation-induced malignancies. With an extreme clinical variability even within families, the genotype-phenotype correlation is complex in NF1. A few correlations have been identified thus far. A more severe phenotype occurs in NF1 patients who have a microdeletion (5-10\% of patients) due to a loss of approximately 1.5 $\mathrm{Mb}$ at $17 \mathrm{q}$ including the NF1 gene, whereas a milder phenotype is observed in NF1 patients with a common 3bp in frame deletion in exon 17. Other genotype-phenotype correlations have been described for spinal neurofibromatosis, optic pathway gliomas, and Watson syndrome. The life expectancy of individuals with NF1 is about 8 years lower compared with the general population. ${ }^{30}$

A NF1-Noonan syndrome phenotype occurs in approximately $12 \%$ of individuals with NF1 and is caused by NF1 mutations. Affected individuals have a phenotype that combines NF1 and Noonan syndrome including ocular hypertelorism, down-slanting palpebral fissures, low-set ears, webbed neck, and pulmonic stenosis.

\section{Neurofibromatosis Type 2}

The hallmark of NF2 is (bilateral) vestibular schwannoma, which typically present with hearing disabilities, tinnitus, and balance dysfunction in patients by their third decades. NF2 is generally considered an adult-onset disease, however, in childhood skin features (schwannomas and café-au-lait spots) and ocular findings (cataract, strabismus, and amblyopia) may be evident but remain often unrecognized. ${ }^{31,32}$ Dermatological and ophthalmological manifestations can sometimes resemble NF1. ${ }^{33,34}$ Furthermore in children, palsy due to mononeuropathy is an increasingly recognized finding. As most patients (50-75\%) develop (often multiple) meningioma, any childhood meningioma should be considered as a possible early sign of NF2. Two-third of NF2 patients develop spinal tumors, both with extramedullary (schwannoma and less frequent meningioma) and intramedullary (ependymoma and rarely pilocytic or diffuse astrocytoma) localization. Penetrance is almost $100 \%$. Truncating mutations have been associated with earlier onset and more NF2associated tumors. ${ }^{34}$ Furthermore, when NF2 presents in children, the phenotype is usually more severe because of symptoms of meningioma. ${ }^{35}$ With earlier diagnosis and novel therapeutic strategies such as cochlear and brain stem implants, life expectancy and quality of life has improved considerably. Still, many NF2 patients have a limited survival (15 years after initial diagnosis).

\section{Rhabdoid Tumor Predisposition Syndrome and Schwannomatosis}

In early childhood, RTPS is characterized by an increased risk for developing malignant rhabdoid tumors (MRTs). MRTs may be localized in the kidney, extra renal but intra-abdominally or in the CNS. CNS-localized MRTs are called atypical teratoid/ rhabdoid tumors (AT/RTs), which are highly malignant and have a limited survival, despite aggressive multimodality therapy (surgery, irradiation, and chemotherapy). AT/RTs generally present before the age of 3 years, an age at which radiation therapy is relatively contraindicated because of an increased vulnerability to long-term neurocognitive deficits. $^{36}$ Penetrance is highly variable. ${ }^{13}$ In children with an AT/RT in which no SMARCB1 mutation is found, germline mutations in SMARCA4 may be considered. ${ }^{37}$ In families with RTPS, choroid plexus carcinoma (CPC), infratentorial medulloblastoma and supratentorial primitive neuroectodermal tumors (PNETs) have been reported as well. ${ }^{38}$ However, it is possible that these cases because of similar histologies have been misdiagnosed and may in fact represent AT/RTs with a prominent epithelial component, as was afterward shown for the medulloblastoma reported in that study. ${ }^{39}$

SMARCB1 germline mutations are also found in 40 to $50 \%$ of families with schwannomatosis (previously referred to as NF3). ${ }^{40,41}$ The main distinction with NF2 is that schwannoma in RTPS are generally not localized at the nervus vestibularis. ${ }^{41,42}$ At adult age, sometimes meningioma, preferentially located at the falx, may be seen. ${ }^{43}$ At this moment, only three families have been described with a combined phenotype of both RTPS and schwannoma. This suggests that the combined phenotype is rare. However, if RTPS patients survive, they may suffer at adult age from schwannoma. ${ }^{41}$ A genotypephenotype correlation likely explains why not in all schwannomatosis families the risk for MRT is increased. ${ }^{13}$ Germline mutations in SMARCB1 and related genes have been found to cause Coffin-Siris syndrome, ${ }^{44}$ but until now no individual with a molecularly confirmed syndrome diagnosis has developed an AT/RT malignancy. ${ }^{45}$

\section{von Hippel-Lindau Disease}

von Hippel-Lindau Disease (VHL) disease is characterized by hemangioblastomas of the CNS and retina, pheochromocytoma, renal cysts and clear cell carcinoma, and other visceral cysts. Penetrance of VHL is close to $100 \%$. At the age of 65 years, most patients have VHL-related manifestations. However, the manifestations and severity are highly variable both within and between families. Although hemangioblastomas typically occur in young adults, the occurrence of a hemangioblastoma in a child or adolescent should point to VHL as multiple hemangioblastomas are likely to develop. ${ }^{46}$ Most VHL patients have multiple hemangioblastomas, which are localized in the brain stem, spinal cord, and nerve roots, compared with sporadic hemangioblastomas which are generally localized in the cerebellum. Hemangioblastomas are frequently accompanied by cysts which can cause symptoms because of their rapid growth. To avoid cysts to recur, complete surgical removal of the hemangioblastomas is essential, and gamma knife treatment is not sufficient. On the basis of genotype, four different VHL phenotypes have been suggested to predict the likelihood to develop pheochromocytoma or renal cell carcinoma. Median life expectancy is significantly lower in VHL patients, ${ }^{30}$ as approximately $70 \%$ of individuals with VHL develop renal cell carcinoma which is the major cause of death.

\section{Tuberous Sclerosis Complex}

Patients with tuberous sclerosis complex (TSC) develop multiple hamartomas, mainly in the brain (70\%), heart (30\%) and 
eyes (50\%), and renal (60\%) and skin abnormalities (nearly $100 \%$ ). At birth, hypomelanotic macules, sometimes only visible with a Wood lamp, may be present. Before the age of 15 years most children with TSC have manifestations. ${ }^{47}$ Epilepsy (up to $80 \%$ ), intellectual disability (40\%), and behavioral problems due to cortical tubers, subependymal hamartomatous nodules and intracranial calcifications are frequently seen. Penetrance is thought to be $100 \%$. TSC exhibits extreme variability in clinical findings both among and within families. The severe end of the spectrum is represented by the classic triad consists of seizures, intellectual disability, and angiofibroma. Patients with TSC1 mutations are usually less severely affected than patients with TSC2 mutations, and females tend to have milder disease than males. In 10 to $15 \%$ of individuals with TSC, usually within the first two decades of life, a subependymal giant cell astrocytoma (SEGA) may be detected. SEGA is a benign, slowly growing tumor, typically arising unilateral or bilateral in the wall of the lateral ventricles, and virtually pathognomonic of TSC. ${ }^{48}$ Treatment of enlarging SEGAs may consist of mammalian target of rapamycin (mTOR) inhibitors; if size causes life-threatening neurologic symptoms neurosurgery is unambiguously indicated.

\section{Li-Fraumeni Syndrome}

LFS is characterized by multiple primary tumors in children and young adults. The predominant tumors are brain tumors, bone and soft tissue sarcomas, breast, and adrenocortical tumors. Half of LFS-associated malignancies are estimated to occur before the age of 30 years. Individuals with LFS are at increased risk of developing various types of generally highly malignant brain tumors (astrocytomas, glioblastomas, medulloblastomas, CPC). The median age of onset for brain tumors is 16 years, suggesting that more than half of LFS-associated brain tumors occur in children younger than 18 years. The risk for brain tumors has been reported to be increased if the TP53 mutation lies in the DNA-binding loop that contacts the minor groove of DNA. Children with a CPC, who typically present at young age ( $\leq 3$ years), are at high risk to harbor a TP53 germline mutation, even in the absence of a positive family history, due to de novo mutations. ${ }^{49,50}$ In a recent report, TP53 germline mutations were also found children with medulloblastoma of the sonic hedgehog subtype (SHH-MB) with chromothripsis. ${ }^{51}$ In SHH-MB, typically presenting between 5 and 18 years of age, $12 \%$ of TP53 germline mutations were identified. ${ }^{52}$ Overall, LFS is known to give a high lifetime risk for a range of tumors: $93 \%$ in woman and $75 \%$ in men, with an estimated 30 to $40 \%$ risk for cancer in childhood and adolescence. ${ }^{53}$ In LFS affected family members, the risk to develop a second or third malignancy was estimated to be 15 and $4 \%$, respectively. For 30 childhood cancer survivors, these risks were considerably higher (57 and 38\%). Various genotypephenotype correlations have been reported. Because of the high risk to develop (multiple) malignant tumors, overall survival is limited. Preliminary studies have shown positive aspects of early diagnosis and surveillance in LFS patients for overall survival. ${ }^{53}$ In LFS patients, exposure to diagnostic and therapeutic radiation should be minimized to avoid the risk of radiation-induced malignancies.

\section{Gorlin Syndrome}

Individuals with GS (nevoid basal cell carcinoma syndrome) have congenital abnormalities such as bifid or fused ribs or wedge-shaped vertebra (> 50\%), often macrocephaly (> 50\% above $>97$ th percentile), sometimes cleft lip and/or palate (5\%) and polydactyly (5\%). Jaw keratocysts develop around their teens; sporadic reports of ameloblastoma arising in these are known. Generally, basal cell carcinoma of the skin are seen starting in adolescence or early adulthood, unless prior exposure to radiotherapy. Palmar and plantar pits can be seen in most patients ( - Fig. 2A). Approximately $5 \%$ of GS patients present during their first years of life with a medulloblastoma. These medulloblastomas have desmoplastic histology with an expression pattern indicating activation of the sonic hedgehog signaling pathway and have a more favorable prognosis compared with their sporadic counterparts. Treatment of medulloblastoma exists of surgical resection, (intrathecal) chemotherapy and irradiation in indicated cases (e.g., metastatic cases or residual disease after surgery)..$^{54}$ It has been suggested that young children presenting with medulloblastoma of nodular or desmoplastic histology need to be assessed for GS. ${ }^{54,55}$ In PTCH1-negative children younger than the age of 3 years with a desmoplastic/nodular medulloblastoma, with and without other manifestations fitting GS, germline mutations in suppressor of fused homolog (SUFU) have been identified. Nontumor CNS manifestations include

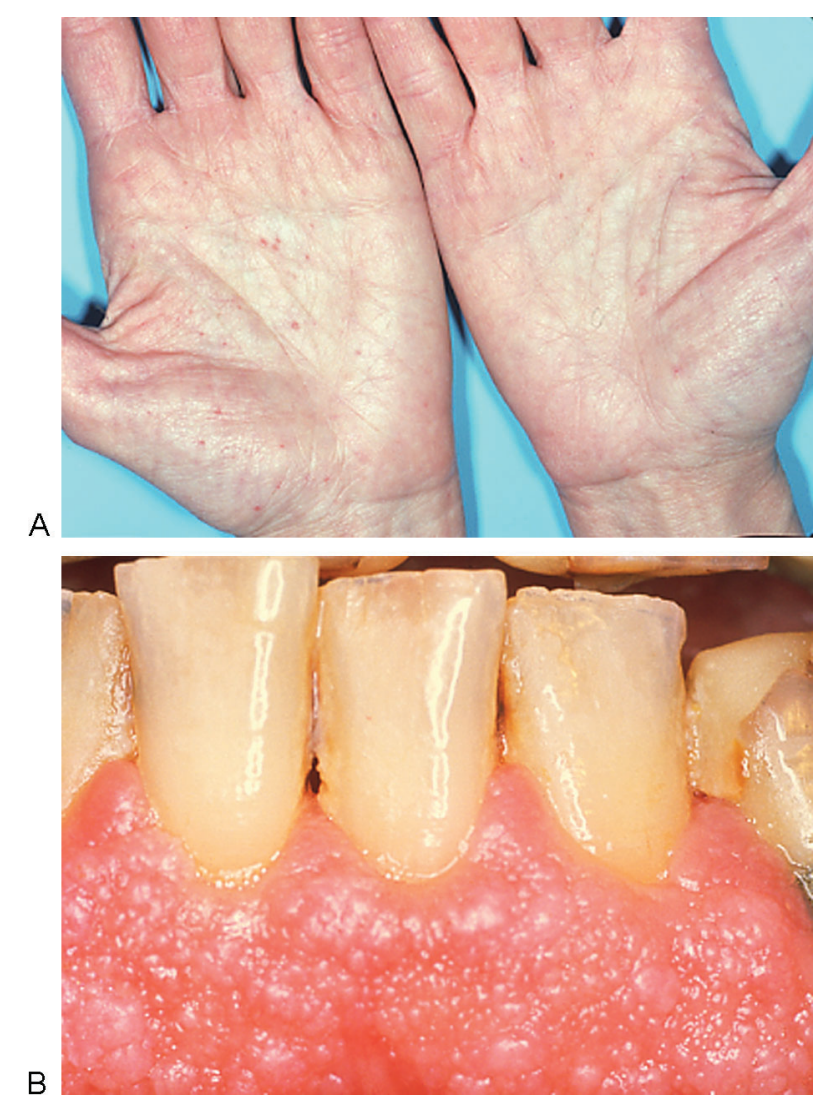

Fig. 2 Various nonneurological signs that can be seen at regular outpatient contacts in children (and/or their parents) with tumor predisposition syndromes causing brain tumors. Palmar pits as can be seen in Gorlin syndrome (A), and mucosal lesions at the gingiva in Cowden syndrome (B). 
calcification of the falx cerebri or tentorium cerebellum, present in $90 \%$ of individuals by the age of 20 years. Meningioma are also reported to occur with an increased frequency in GS patients, furthermore, incidental cases of astrocytomas, oligodendroglioma, and craniopharyngioma have been reported. Penetrance is probably $100 \%$, and expression is highly variable also within a single family. Except for an increased chance for intellectual disability in individuals with a microdeletion that include PTCH1, no genotype-phenotype correlations have been recognized. Patients with GS generally have a good prognostic outcome with (near) normal life expectancy. ${ }^{30}$

\section{Cowden Syndrome}

Cowden syndrome (CS) is one of the clinical manifestations of the phosphatase and tensin homolog (PTEN) hamartoma tumor syndromes and is characterized by multiple hamartomas and a high risk for benign and malignant tumors of predominantly the thyroid, breast, and endometrium. Patients with CS usually present by their 20s when mucocutaneous manifestations (-Fig. 2B) have been developed. Dysplastic gangliocytoma of cerebellum, also known as Lhermitte-Duclos disease (LDD), is the pathognomonic CNS manifestation of CS. LDD is a rare benign hamartomatous overgrowth composed of dysplastic ganglion cells in the cerebellum and usually arises at adult age, but affected children do occur. Sporadically occurring meningioma, medulloblastoma, gangliocytoma, and glioblastoma have been reported at adult age in patients with CS. Additional cerebral manifestations of CS include macrocephaly in 20 to $70 \%$ of cases (often skull circumferences are three standard deviation or more above the mean), hydrocephalus, intellectual disability, autism, and seizures. In children diagnosed with CS, neurodevelopmental evaluation is generally useful. An age-dependent penetrance has been observed, becoming complete in the late fourth decade. Because of the variable and often subtle external manifestations of CS, many individuals remain undiagnosed. ${ }^{56}$ Both the presence of a germline mutation (in $85 \%$ of patients who fulfil the diagnostic criteria of CS a mutation is identified) and the location of the mutation are associated with severity of disease. Because of the risk to develop (multiple) malignant (extra-CNS) tumors survival is limited.

\section{Turcot Syndrome}

Turcot syndrome is characterized by the co-occurrence of a primary brain tumor and (multiple) colorectal adenoma(s) or carcinoma. ${ }^{57}$ This association was described as possible result from two germline defects: mismatch-repair gene mutations or APC mutations. The pathology of the CNS tumor may help distinguish between the underlying genetic cause. Medulloblastoma are generally associated with APC mutations, whereas glioblastoma are usually associated with mismatch repair gene mutations. ${ }^{58}$ It is important to note that in the original consanguineous family described by Turcot et al, ${ }^{57}$ one child developed at 15 years multiple polyps with two adenocarcinoma and a spinal medulloblastoma and his sister had multiple polyps at 13 years and developed a glioblastoma at the of age 21 years. We think that this family suffered from constitutional mismatch repair-deficiency syndrome (CCMR-D) and that the term Turcot syndrome should be revised. Thus far, however, the term Turcot syndrome is being used for the cooccurrence of a primary brain tumor and (multiple) colorectal adenoma(s) or carcinoma. Of note, the association of brain tumors and colon cancer also may occur in LFS, but in this context the term Turcot syndrome is generally not used.

\section{Lynch syndrome}

Lynch syndrome (LS; previously known as hereditary nonpolyposis colorectal cancer) predisposes to colorectal cancer and other tumor types (as endometrial, gastric, ovarian, urinary tract, small bowel, pancreas, breast, and sebaceous skin neoplasias). Also brain tumors are associated with LS. ${ }^{58,59}$ Glioma, predominantly glioblastoma, but also ependymoma, high grade astrocytoma and oligodendroglioma, and incidental cases of ganglioma, meningioma, and hemangioblastoma are described in LS. ${ }^{60,61}$ LS is quite common (3-5\% of colorectal cancer cases are caused by LS), but a CNS tumor as primary manifestation, especially in children, has not been reported. ${ }^{61}$ In adolescents with LS glioblastoma are sporadically described, this may be due to an unidentified constitutional mismatch repair-deficiency syndrome (CMMR-D).

\section{Constitutional Mismatch Repair-Deficiency Syndrome}

CMMR-D is caused by mutations of both alleles of one of the four mismatch repair genes. This causes a more severe phenotype with tumors at young age. Children resemble the NF1 phenotype with café-au-lait spots. A minority also have freckling, Lisch nodule, or neurofibroma, although generally no other NF1 features have been seen. ${ }^{62}$ Children develop various tumors, predominantly hematological malignancies, brain tumors, and colorectal carcinoma around the age of 10 years. Other LS-associated and not LS-associated tumors are reported in CMMR-D (reviewed in Wimmer and Etzler $^{62}$ ). The risk to develop a second malignancy is high. ${ }^{62,63}$ Brain tumors observed at a mean age of 8 years are glioma, predominantly glioblastoma, medulloblastoma, and supratentorial PNET. 62 Pedigree analysis and sometimes parental consanguinity may point to autosomal recessive inheritance; however, with low penetrant mutations negative family histories for LS are common. ${ }^{64}$

\section{Familial Adenomatous Polyposis}

Familial adenomatous polyposis (FAP) patients generally have a colorectum carpeted by hundreds to thousands of polyps, which without treatment will lead to colorectal carcinomas. Polyps are usually first detected in adolescence. However, in rare cases the first manifestation of FAP is a medulloblastoma in childhood. Children presenting with medulloblastomas having no evidence of polyps is of poor prognosis. ${ }^{65}$ Extracolonic (non)neoplastic manifestations as osteoma, hepatoblastomas, ampulla of vater carcinomas, desmoid tumors, and epidermoid cysts are also associated with $A P C$ germline mutations ${ }^{66}$ and are known as Gardner syndrome. ${ }^{67}$ Efforts are being made to further delineate the observed genotype-phenotype correlation thus far. Several cases of craniopharyngioma in the cerebellopontine angle ${ }^{68}$ and also meningioma ${ }^{69,70}$ were reported in Gardner 
syndrome. Gliomas have been incidentally reported as well, however, this may be erroneous because of confusion in Turcot syndrome. The life-expectancy in FAP patients has significantly increased in the past decennia because of preventive surgical options and ameliorated screening.

\section{Discussion}

In 5 to $10 \%$ of children with cancer an underlying genetic syndrome has been suggested. ${ }^{12,71,72}$ The development of new molecular techniques and more stringent diagnostic efforts may well cause a further increase of this percentage. This article demonstrates that also in children with brain tumors a significant number of syndromes can be diagnosed, with wide-spread consequences. Merks et al and Méhes ${ }^{12,73}$ have recommended that all children diagnosed with a tumor should be assessed by a clinical geneticist or a pediatrician skilled in clinical morphology.

In some cases, the tumor type itself pinpoints to an underlying syndrome. An example is a child with a CPC, who has a high likelihood to have a germline mutation in TP53 causing LFS even in the absence of a family history suggestive of LFS. Another example is formed by dysplastic gangliocytoma of cerebellum (LDD) which is a pathognomic CNS manifestation of CS. In other cases, various morphological abnormalities may pinpoint to recognizable syndromes. ${ }^{11,12,14}$ Several CNS tumor predisposition syndromes (such as GS, NF1, NF2, TSC, and VHL) have dermatological manifestations, which can be expected due to their joint embryological origin and are referred to as neurocutaneous syndromes or phakomatoses. ${ }^{71}$ Consultation of a dermatologist may be helpful in diagnosing such entities. Absence of skin anomalies does not exclude every phakomatosis completely however, and further studies may still be indicated. The same holds for various other anomalies in tumor predisposing syndromes: it is uncommon that a manifestation is an absolute prerequisite for an entity, and absence does not exclude the entity with certainty. Referral to a clinical geneticist, who is also specialized in obtaining detailed family histories and combines seemingly unrelated data from patients and family members, needs to be considered. ${ }^{71}$ An example is the combination of medulloblastoma in a child and young age onset breast cancer and sarcoma in family members, which fulfils LFS criteria.

Once a clinical diagnosis is made or suspected, DNA diagnostics is generally subsequently performed to confirm this. Interpretation of molecular results, particularly of unclassified variants which may be identified in DNA diagnostics, can be difficult. The absence of a likely pathogenic variant in a gene which fits very well the clinical phenotype should not immediately lead to the rejection of the gene as the cause and asks for further analyses. We have also learned that we cannot always rely on investigating DNA derived from lymphocytes in the blood: sometimes a mutation is detectable only in other (tumor) tissues (mosaicism). Well-known examples are Proteus syndrome ${ }^{74}$ and Cornelia de Lange syndrome, ${ }^{75}$ but it has also been described in segmental NF1 ${ }^{76}$ and NF2. ${ }^{77}$ Evaluation of results of recently developed techniques such as next-generation sequencing, especially wholeexome sequencing, asks for a careful interplay between molecular geneticist, bioinformatician and clinician. Wholeexome sequencing is used in diagnostics for well-known entities for which the causative gene was not identified. ${ }^{51,78,79}$ Whole-exome sequencing may also be considered in families with a phenotype in which regular clinical and molecular diagnostics have failed to find the cause. A commonly used strategy is checking genes acting in the same pathway(s) as the genes known to cause such phenotypes. An example can be a patient with a phenotype that resembles CS but who has no detectable PTEN mutation. Whole-exome sequencing in such patients has learned that germline mutations in PIK3CA and AKT1, both belonging to the PTEN/PI3K/ AKT pathway can be found. ${ }^{74}$ Undoubtedly, further genes acting in this pathway will be found in other, clinically similar patients. The present molecular techniques allow for much more rapid detection of causative genes in rare entities and indeed the number of genes known to cause syndromes is growing enormously. It has led to the understanding that deletions of tumor suppressor genes can cause tumor predisposition phenotypes in the same way as mutations in these genes can do. We also understand now that clinically different entities can be caused by mutations in the same gene. For example, both Turcot and Gardner syndromes can be seen as tails of the FAP spectrum caused by APC mutations. In addition, mutations in SMARCB1 are not only known to be responsible for RTPS and schwannomatosis, but also play a role in other diseases including Coffin-Siris syndrome (CSS). ${ }^{44}$ In CSS no increased risk of schwannomas or MRTs has been noticed; however, a medulloblastoma in a child with CSS that was not molecularly confirmed has been described ( - Table $\mathbf{1}){ }^{80}$

Diagnosing tumor predisposition syndromes in children has several important consequences. ${ }^{71}$ First, syndrome-associated malignancies may have a different prognosis and require specific treatments. Elevated risks for developing secondary malignancies after treatment of the primary tumor may influence the choice of chemotherapy or radiation. Optic nerve gliomas may serve as an example. If treatment is required, optic nerve gliomas are generally treated with radiotherapy, but in the context of NF1, radiotherapy, should be avoided. ${ }^{81}$ In several other tumor predisposition syndromes (NF2, LFS, and GS) irradiation should be avoided as well, especially in childhood, as this may induce, accelerate, or transform tumors in children with an inactive tumor suppressor gene. Furthermore, increased intrinsic radiosensitivity and chemosensitivity to standard treatment can be seen in syndromes as Nijmegen breakage syndrome and ataxia telangiectasia (-Table 1), in which DNA repair genes are nonfunctional. In such entities, standard treatments need to be adjusted, otherwise severe unexpected, potentially fatal, toxicity may be observed. ${ }^{82}$ Second, some tumor predisposition syndromes require screening for subsequent malignancies. The mere knowledge of the presence of any of the tumor predisposition syndromes listed in - Table 2 in a child will elicit increased vigilance to warning signs that may reflect an underlying malignancy. If radioimaging is indicated as part of 
Table 4 Take-home messages

\section{Take-home messages}

- Genetic factors play a significant role in the etiology of brain tumors in children.

- Every child who develops a brain tumor should be evaluated for signs and symptoms pointing to a syndrome with more widespread consequences and by taking a detailed family history.

- A significant number of syndromes are associated with an increased risk to develop a brain tumor as a child.

- Counselling patients with syndromes should also include information about (possible) liabilities to develop tumors and other syndrome manifestations both in the patients and their family members.

- Screening recommendations are available only for the most prevalent tumor predisposition syndromes; screening should be determined on an individual basis after multidisciplinary consultation and taking data on the patient and family into account.

surveillance, MRI imaging is recommended instead of computed tomographic scanning due to the risk for radiationinduced malignancies in most tumor predisposition syndromes. Third, the other, nontumor manifestations of the syndrome may require surveillance or even preventive measurements as well. As example, NF1 individuals should be regularly checked for the development of hypertension due to a higher risk of vascular abnormalities. Finally, tumor predisposition syndromes are hereditary disorders, and siblings, parents, and other family members may be affected as well. Most tumor predisposition syndromes follow an autosomal dominant pattern of inheritance and have recurrence risks of $50 \%$ for offspring of an affected individual. If the germline mutation is not de novo, there is a recurrence risk of $50 \%$ for all other first degree family members. These family members should be informed about their increased risks to develop cancer, and preventive (screening) options. Prenatal diagnostics and preimplantation diagnostics are options to consider in order not to pass the tumor predisposition syndrome on to offspring. Genetic testing can bring along ethical issues, ${ }^{83}$ insecurities on prognosis and quality of life, and patients and their relatives may be hesitant to get tested. Genetic counselling may help them to make the right choices for them in these ethical dilemmas.

A large amount of tumors has been sequenced in the search for therapeutic targets ${ }^{84}$ and more studies will probably follow. In those studies, many somatic "driver" mutations are described; however, germline mutations are hardly reported and not generally checked for in research basis. ${ }^{85}$ Our ameliorated knowledge of the etiology of cancer is increasingly translated into management strategies in tumor predisposition syndromes. ${ }^{53}$ Textbooks (such as Management of Genetic Syndromes by Cassidy and Allanson) ${ }^{86}$ and sites (such as Orphanet, http://www.orpha.net/consor/cgi-bin/home. php) are available that describe the general care for individuals with one of the various syndromes described above. Small molecule inhibitors, that act against a particular function of a protein causing tumors, have been developed and are being tested, also in tumor predisposition syndromes. ${ }^{87}$ For example, a range of small molecule inhibitors are tested in clinical trials to inhibit growth of neurofibroma and vestibular schwannoma in individuals with $\mathrm{NF}^{88}$ and NF2, respectively. ${ }^{89}$ In TSC, loss of function mutations in TSC1/TSC2, encoding for the proteins hamartin and tuberin, disrupt the complex of these two proteins and activate mTOR signaling. Indeed,
MTOR inhibitors have shown to induce partial regression of SEGA in TSC. ${ }^{90}$ It is conceivable that in the near future, such strategies are not only based on this knowledge but also on the specific mutation(s) found in an individual, and that personalized therapy will become possible for tumor predisposition syndromes, also in children ( - Table 4 ).

\section{Conflicts of Interest}

There are no conflicts of interest to be reported.

\section{References}

1 Vogelstein B, Kinzler KW. The Genetic Basis of Human Cancer. 2nd ed. New York, NY: McGraw-Hill; 2002

2 Fleming AJ, Chi SN. Brain tumors in children. Curr Probl Pediatr Adolesc Health Care 2012;42(4):80-103

3 Garber JE, Offit K. Hereditary cancer predisposition syndromes. J Clin Oncol 2005;23(2):276-292

4 Ponder BA. Cancer genetics. Nature 2001;411(6835):336-341

5 Knudson AG Jr. Mutation and cancer: statistical study of retinoblastoma. Proc Natl Acad Sci U S A 1971;68(4):820-823

6 Foulkes WD. Inherited susceptibility to common cancers. N Engl J Med 2008;359(20):2143-2153

7 Eng C, Ponder BA. The role of gene mutations in the genesis of familial cancers. FASEB J 1993;7(10):910-919

8 Hennekam RCM, Allanson JE, Krantz ID. Gorlin's Syndromes of the Head and Neck. 5th ed. New York, NY: Oxford University Press Inc.; 2010

9 Agha MM, Williams JI, Marrett L, To T, Zipursky A, Dodds L. Congenital abnormalities and childhood cancer. Cancer 2005; 103(9):1939-1948

10 Altmann AE, Halliday JL, Giles GG. Associations between congenital malformations and childhood cancer. A register-based casecontrol study. Br J Cancer 1998;78(9):1244-1249

11 Merks JH, Ozgen HM, Koster J, Zwinderman AH, Caron HN, Hennekam RC. Prevalence and patterns of morphological abnormalities in patients with childhood cancer. JAMA 2008;299(1):61-69

12 Merks JH, Caron HN, Hennekam RC. High incidence of malformation syndromes in a series of 1,073 children with cancer. Am J Med Genet A 2005;134A(2):132-143

13 Bourdeaut $\mathrm{F}$, Lequin $\mathrm{D}$, Brugières L, et al. Frequent hSNF5/INI1 germline mutations in patients with rhabdoid tumor. Clin Cancer Res 2011;17(1):31-38

14 Merks JH, Ozgen HM, Cluitmans TL, et al. Normal values for morphological abnormalities in school children. Am J Med Genet A 2006;140(19):2091-2109

15 Dolecek TA, Propp JM, Stroup NE, Kruchko C. CBTRUS statistical report: primary brain and central nervous system tumors diagnosed in the United States in 2005-2009. Neuro-oncol 2012;14 (Suppl 5):v1-v49 
16 Howlader N, Noone AM, Krapcho M, et al. SEER Cancer Statistics Review, 1975-2010. National Cancer Institute. Available at: http:// seer.cancer.gov/csr/1975_2010/ based on November 2012 SEER data submission, posted to the SEER web site, April 2013.

17 Kieran MW, Walker D, Frappaz D, Prados M. Brain tumors: from childhood through adolescence into adulthood. J Clin Oncol 2010; 28(32):4783-4789

18 Semerci CN, Bebitoglu I, Kaçar A, et al. An unusual fetus with complete absence of thoracic, lumbar and sacral vertebrae, bilateral renal agenesis, VSD, meningomyelocele, imperforate anus, and teratoma. Clin Dysmorphol 2001;10(1):57-60

19 Blount JP, Elton S. Spinal lipomas. Neurosurg Focus 2001;10(1):e3

20 Goyal N, Singh PK, Kakkar A, Sharma MC, Mahapatra AK. Mature teratoma in association with neural tube defect (occipital encephalocele): series of four cases and review of the literature. Pediatr Neurosurg 2012;48(2):67-72

21 Villavicencio EH, Walterhouse DO, Iannaccone PM. The sonic hedgehog-patched-gli pathway in human development and disease. Am J Hum Genet 2000;67(5):1047-1054

22 Poduri A, Evrony GD, Cai X, Walsh CA. Somatic mutation, genomic variation, and neurological disease. Science 2013;341(6141): 1237758

23 Winter RM, Baraitser M. The London Dysmorphology Database. J Med Genet 1987;24(8):509-510

24 Louis DN, Ohgaki H. WHO Classification of Tumours of the Central Nervous System. Lyon, France: IARC Press; 2007

25 Hopman SM, Merks JH, de Borgie CA, et al. The development of a clinical screening instrument for tumour predisposition syndromes in childhood cancer patients. Eur J Cancer 2013;49(15): 3247-3254

26 Steliarova-Foucher E, Stiller C, Lacour B, Kaatsch P. International classification of childhood cancer, third edition. Cancer 2005; 103:1457-1467

27 Lubs ML, Bauer MS, Formas ME, Djokic B. Lisch nodules in neurofibromatosis type 1. N Engl J Med 1991;324(18):1264-1266

28 Carli M, Ferrari A, Mattke A, et al. Pediatric malignant peripheral nerve sheath tumor: the Italian and German soft tissue sarcoma cooperative group. J Clin Oncol 2005;23(33):8422-8430

29 Porter DE, Prasad V, Foster L, Dall GF, Birch R, Grimer RJ. Survival in Malignant Peripheral Nerve Sheath Tumours: A Comparison between Sporadic and Neurofibromatosis Type 1-Associated Tumours. Sarcoma 2009;2009:756395

30 Wilding A, Ingham SL, Lalloo F, et al. Life expectancy in hereditary cancer predisposing diseases: an observational study. J Med Genet 2012;49(4):264-269

31 Ruggieri M, lannetti P, Polizzi A, et al. Earliest clinical manifestations and natural history of neurofibromatosis type 2 (NF2) in childhood: a study of 24 patients. Neuropediatrics 2005;36(1): 21-34

32 Evans DG, Birch JM, Ramsden RT. Paediatric presentation of type 2 neurofibromatosis. Arch Dis Child 1999;81(6):496-499

33 Asthagiri AR, Parry DM, Butman JA, et al. Neurofibromatosis type 2. Lancet 2009;373(9679):1974-1986

34 Evans DG. Neurofibromatosis 2 [Bilateral acoustic neurofibromatosis, central neurofibromatosis, NF2, neurofibromatosis type II]. [Bilateral acoustic neurofibromatosis, central neurofibromatosis, NF2, neurofibromatosis type II] Genet Med 2009;11(9):599-610

35 Baser ME, Friedman JM, Aeschliman D, et al. Predictors of the risk of mortality in neurofibromatosis 2. Am J Hum Genet 2002;71(4): 715-723

36 De Amorim Bernstein K, Sethi R, Trofimov A, et al. Early clinical outcomes using proton radiation for children with central nervous system atypical teratoid rhabdoid tumors. Int J Radiat Oncol Biol Phys 2013;86(1):114-120

37 Hasselblatt M, Gesk S, Oyen F, et al. Nonsense mutation and inactivation of SMARCA4 (BRG1) in an atypical teratoid/rhabdoid tumor showing retained SMARCB1 (INI1) expression. Am J Surg Pathol 2011;35(6):933-935
38 Sévenet N, Sheridan E, Amram D, Schneider P, Handgretinger R, Delattre O. Constitutional mutations of the hSNF5/INI1 gene predispose to a variety of cancers. Am J Hum Genet 1999;65(5): $1342-1348$

39 Gessi M, Giangaspero F, Pietsch T. Atypical teratoid/rhabdoid tumors and choroid plexus tumors: when genetics "surprise" pathology. Brain Pathol 2003;13(3):409-414

40 Hulsebos TJ, Plomp AS, Wolterman RA, Robanus-Maandag EC, Baas F, Wesseling P. Germline mutation of INI1/SMARCB1 in familial schwannomatosis. Am J Hum Genet 2007;80(4):805-810

41 Plotkin SR, Blakeley JO, Evans DG, et al. Update from the 2011 International Schwannomatosis Workshop: From genetics to diagnostic criteria. Am J Med Genet A 2013;161A(3):405-416

42 MacCollin M, Chiocca EA, Evans DG, et al. Diagnostic criteria for schwannomatosis. Neurology 2005;64(11):1838-1845

43 van den Munckhof P, Christiaans I, Kenter SB, Baas F, Hulsebos TJ Germline SMARCB1 mutation predisposes to multiple meningiomas and schwannomas with preferential location of cranial meningiomas at the falx cerebri. Neurogenetics 2012;13(1):1-7

44 Tsurusaki Y, Okamoto N, Ohashi $\mathrm{H}$, et al. Mutations affecting components of the SWI/SNF complex cause Coffin-Siris syndrome. Nat Genet 2012;44(4):376-378

45 Santen GWE, Aten E, Vulto-van Silfhout AT, et al; Coffin-Siris consortium. Coffin-Siris syndrome and the BAF complex: genotype-phenotype study in 63 patients. Hum Mutat 2013;34(11): 1519-1528

46 Kanno H, Kuratsu J, Nishikawa R, et al. Clinical features of patients bearing central nervous system hemangioblastoma in von HippelLindau disease. Acta Neurochir (Wien) 2013;155(1):1-7

47 Ahlsén G, Gillberg IC, Lindblom R, Gillberg C. Tuberous sclerosis in Western Sweden. A population study of cases with early childhood onset. Arch Neurol 1994;51(1):76-81

48 Ichikawa T, Wakisaka A, Daido S, et al. A case of solitary subependymal giant cell astrocytoma: two somatic hits of TSC2 in the tumor, without evidence of somatic mosaicism. J Mol Diagn 2005; 7(4):544-549

49 Russell-Swetek A, West AN, Mintern JE, et al. Identification of a novel TP53 germline mutation E285V in a rare case of paediatric adrenocortical carcinoma and choroid plexus carcinoma. J Med Genet 2008;45(9):603-606

50 Schniederjan MJ, Shehata B, Brat DJ, Esiashvili N, Janss AJ. De novo germline TP53 mutation presenting with synchronous malignancies of the central nervous system. Pediatr Blood Cancer 2009; 53(7):1352-1354

51 Rausch T, Jones DT, Zapatka M, et al. Genome sequencing of pediatric medulloblastoma links catastrophic DNA rearrangements with TP53 mutations. Cell 2012;148(1-2):59-71

52 Zhukova N, Ramaswamy V, Remke M, et al. Subgroup-specific prognostic implications of TP53 mutation in medulloblastoma. J Clin Oncol 2013;31(23):2927-2935

53 Villani A, Tabori U, Schiffman J, et al. Biochemical and imaging surveillance in germline TP53 mutation carriers with Li-Fraumeni syndrome: a prospective observational study. Lancet Oncol 2011; 12(6):559-567

54 Garrè ML, Cama A, Bagnasco F, et al. Medulloblastoma variants: age-dependent occurrence and relation to Gorlin syndrome-a new clinical perspective. Clin Cancer Res 2009;15(7):2463-2471

55 Brugières L, Remenieras A, Pierron G, et al. High frequency of germline SUFU mutations in children with desmoplastic/nodular medulloblastoma younger than 3 years of age. J Clin Oncol 2012; 30(17):2087-2093

56 Merks JH, de Vries LS, Zhou XP, et al. PTEN hamartoma tumour syndrome: variability of an entity. J Med Genet 2003;40(10):e111

57 Turcot J, Despres JP, St Pierre F. Malignant tumors of the central nervous system associated with familial polyposis of the colon: report of two cases. Dis Colon Rectum 1959;2:465-468

58 Hamilton SR, Liu B, Parsons RE, et al. The molecular basis of Turcot's syndrome. N Engl J Med 1995;332(13):839-847 
59 Schulmann K, Brasch FE, Kunstmann E, et al; German HNPCC Consortium. HNPCC-associated small bowel cancer: clinical and molecular characteristics. Gastroenterology 2005;128(3): 590-599

60 Merlo A, Rochlitz C, Scott R. Survival of patients with Turcot's syndrome and glioblastoma. N Engl J Med 1996;334(11):736-737

61 Vasen HF, Sanders EA, Taal BG, et al. The risk of brain tumours in hereditary non-polyposis colorectal cancer (HNPCC). Int J Cancer 1996;65(4):422-425

62 Wimmer K, Etzler J. Constitutional mismatch repair-deficiency syndrome: have we so far seen only the tip of an iceberg? Hum Genet 2008;124(2):105-122

63 Tan TY, Orme LM, Lynch E, et al. Biallelic PMS2 mutations and a distinctive childhood cancer syndrome. J Pediatr Hematol Oncol 2008;30(3):254-257

64 Krüger S, Kinzel M, Walldorf C, et al. Homozygous PMS2 germline mutations in two families with early-onset haematological malignancy, brain tumours, HNPCC-associated tumours, and signs of neurofibromatosis type 1. Eur J Hum Genet 2008;16(1):62-72

65 Van Meir EG. "Turcot's syndrome": phenotype of brain tumors, survival and mode of inheritance. Int J Cancer 1998;75(1): 162-164

66 Nishisho I, Nakamura Y, Miyoshi Y, et al. Mutations of chromosome 5 q21 genes in FAP and colorectal cancer patients. Science 1991; 253(5020):665-669

67 Gardner EJ. Follow-up study of a family group exhibiting dominant inheritance for a syndrome including intestinal polyps, osteomas, fibromas and epidermal cysts. Am J Hum Genet 1962;14:376-390

68 Bozbuga M, Turan Suslu H, Hicdonmez T, Bayindir C. Primary cerebellopontine angle craniopharyngioma in a patient with Gardner syndrome. J Clin Neurosci 2011;18(2):300-301

69 Kenning TJ, Kanwar VS, Qian J, Deshaies EM. A de novo desmoid tumor of the surgical site following foramen magnum meningioma resection in a patient with Gardner's Syndrome: a case report and review of the literature. J Neurooncol 2009;91(1):107-111

70 Leblanc R. Familial adenomatous polyposis and benign intracranial tumors: a new variant of Gardner's syndrome. Can J Neurol Sci 2000;27(4):341-346

71 D'Orazio JA. Inherited cancer syndromes in children and young adults. J Pediatr Hematol Oncol 2010;32(3):195-228

72 Knapke S, Nagarajan R, Correll J, Kent D, Burns K. Hereditary cancer risk assessment in a pediatric oncology follow-up clinic. Pediatr Blood Cancer 2012;58(1):85-89

73 Méhes K. Malformations in children with cancer. Am J Med Genet A 2006;140(8):932

74 Lindhurst MJ, Sapp JC, Teer JK, et al. A mosaic activating mutation in AKT1 associated with the Proteus syndrome. N Engl J Med 2011; 365(7):611-619

75 Huisman SA, Redeker EJ, Maas SM, Mannens MM, Hennekam RC. High rate of mosaicism in individuals with Cornelia de Lange syndrome. J Med Genet 2013;50(5):339-344
76 Listernick R, Mancini AJ, Charrow J. Segmental neurofibromatosis in childhood. Am J Med Genet A 2003;121A(2):132-135

77 Evans DG, Ramsden RT, Shenton A, et al. Mosaicism in neurofibromatosis type 2: an update of risk based on uni/bilaterality of vestibular schwannoma at presentation and sensitive mutation analysis including multiple ligation-dependent probe amplification. J Med Genet 2007;44(7):424-428

78 Aavikko M, Li SP, Saarinen S, et al. Loss of SUFU function in familial multiple meningioma. Am J Hum Genet 2012;91(3):520-526

79 Zhang J, Wu G, Miller CP, et al; St. Jude Children's Research Hospital-Washington University Pediatric Cancer Genome Project. Whole-genome sequencing identifies genetic alterations in pediatric low-grade gliomas. Nat Genet 2013;45(6):602-612

80 Rogers L, Pattisapu J, Smith RR, Parker P. Medulloblastoma in association with the Coffin-Siris syndrome. Childs Nerv Syst 1988; $4(1): 41-44$

81 Wilhelm H. Primary optic nerve tumours. Curr Opin Neurol 2009; 22(1):11-18

82 Distel L, Neubauer S, Varon R, Holter W, Grabenbauer G. Fatal toxicity following radio- and chemotherapy of medulloblastoma in a child with unrecognized Nijmegen breakage syndrome. Med Pediatr Oncol 2003;41(1):44-48

83 Schiffman JD, Geller JI, Mundt E, Means A, Means L, Means V. Update on pediatric cancer predisposition syndromes. Pediatr Blood Cancer 2013;60(8):1247-1252

84 Alexandrov LB, Nik-Zainal S, Wedge DC, et al; Australian Pancreatic Cancer Genome Initiative; ICGC Breast Cancer Consortium; ICGC MMML-Seq Consortium; ICGC PedBrain. Signatures of mutational processes in human cancer. Nature 2013;500(7463):415-421

85 Bombard Y, Robson M, Offit K. Revealing the incidentalome when targeting the tumor genome. JAMA 2013;310(8):795-796

86 Cassidy SB, Allanson JE. Management of Genetic Syndromes. 3rd ed. Hoboken, NJ: Wiley-Blackwell; 2010

87 Ullrich NJ. Inherited disorders as a risk factor and predictor of neurodevelopmental outcome in pediatric cancer. Dev Disabil Res Rev 2008;14(3):229-237

88 Kim A, Gillespie A, Dombi E, et al. Characteristics of children enrolled in treatment trials for NF1-related plexiform neurofibromas. Neurology 2009;73(16):1273-1279

89 Mautner VF, Nguyen R, Kutta H, et al. Bevacizumab induces regression of vestibular schwannomas in patients with neurofibromatosis type 2. Neuro-oncol 2010;12(1):14-18

90 Jóźwiak S, Nabbout R, Curatolo P; participants of the TSC Consensus Meeting for SEGA and Epilepsy Management. Management of subependymal giant cell astrocytoma (SEGA) associated with tuberous sclerosis complex (TSC): Clinical recommendations. Eur J Paediatr Neurol 2013;17(4):348-352

91 Hennekam RC, Biesecker LG, Allanson JE, et al; Elements of Morphology Consortium. Elements of morphology: general terms for congenital anomalies. Am J Med Genet A 2013;161A(11): $2726-2733$ 